\title{
Student and School Performance Across Countries: a Machine Learning Approach.
}

\author{
Chiara Masci ${ }^{\natural}$, Geraint Johnes ${ }^{\sharp}$, Tommaso Agasisti*
}

January 8, 2018

๒ MOX - Modelling and Scientific Computing, Department of Mathematics, Politecnico di Milano, via Bonardi 9, Milano, Italy

chiara.masci@polimi.it

\# LUMS - Lancaster University Management School, Lancaster, LA1 4YX, United Kingdom g. johnes@lancaster.ac.uk

* Politecnico di Milano, School of Management, via Lambruschini 4/b, Milano, Italy

tommaso.agasisti@polimi.it 


\begin{abstract}
In this paper, we develop and apply novel machine learning and statistical methods to analyse the determinants of students' PISA 2015 test scores in nine countries: Australia, Canada, France, Germany, Italy, Japan, Spain, UK and USA. The aim is to find out which student characteristics are associated with test scores and which school characteristics are associated to school value-added (measured at school level). A specific aim of our approach is to explore non-linearities in the associations between covariates and test scores, as well as to model interactions between school-level factors in affecting results. In order to address these issues, we apply a two-stage methodology using flexible tree-based methods. We first run multilevel regression trees in the first stage, to estimate school value-added. In the second stage, we relate the estimated school valueadded to school level variables by means of regression trees and boosting. Results show that while several student and school level characteristics are significantly associated to students' achievements, there are marked differences across countries. The proposed approach allows an improved description of the structurally different educational production functions across countries.
\end{abstract}

Keywords: Education; Multilevel model; School value-added; Regression trees; Boosting.

JEL-code: C40, I20. 


\section{Introduction}

The educational activity involves a complex process whereby inputs (such as human and financial resources) are converted into outputs. By analogy with the type of production function that is typically used to analyse the technology of a firm, the labour and capital inputs used by a school are likely to influence its output. But, since students themselves form both an input and output, and since they themselves are transformed by the experience of education, such a simple framework fails adequately to capture some key salient features of the process. This is a very well-known challenge in the existent literature about Educational Production Function (EPF). Indeed, the learning process of students is influenced by students' own characteristics, those of their family, their peers, the neighbourhood in which they live, as well as by the characteristics of the school that they are attending. Moreover, the way in which various inputs (at different levels) affect output is likely to vary substantially across the educational systems that operate in different countries. A common characteristic of all educational systems is the hierarchical structure in which students are nested within classes, that are nested within schools, that are in turn nested within cities and so forth. Establishing the structure of such a hierarchy is a non-trivial exercise, not least because this structure may be different across countries. Exploring international datasets which contain information about students' performance in more countries can be a rational approach to understand how the differences among educational systems can have an impact on students' results, all else equal (see [16]).

The Programme for International Student Assessment (PISA) is a triennial international survey (started in 2000) which aims to evaluate education systems worldwide by testing the skills and knowledge of 15-year-old students. In 2015 over half a million students, representing 28 million 15-year-olds in 72 countries and economies, took the internationally agreed two-hour test. Students were assessed in science, mathematics, reading, collaborative problem solving and financial literacy. Moreover, a wide array of data concerning a set of student and school levels characteristics are available, thanks to questionnaires completed by students and school principals.

Our aim in this paper is to identify which are the student and school level characteristics that are related to students' achievement, with the aim of investigating the impact of these characteristics on the outcome. We analyse the school systems of nine large developed countries: Australia, Canada, France, Germany, Italy, Japan, Spain, UK, USA. Specifically, our research questions are:

- Which student level characteristics are related to student achievement?

- How much of the total variability in student achievement can be explained by the difference between schools and how can we estimate the school value-added?

- Which school level characteristics are related to school value-added and 
in what way?

- How do co-factors interact with each other in determining outcomes simultaneously?

- How do these relationships between inputs/covariates and outputs/test scores vary across countries?

In order to address these issues, we run a two stage-analysis, that departs from traditional EPFs approach and embraces a Machine Learning strategy:

1. In the first stage, we apply multilevel regression trees (RE-EM tree, see [36]) in which we consider students (level 1) nested within schools (level 2 ). By means of this model we can both analyse which are the student level variables that are related to student achievements and estimate the school value-added, as a random effect (grouping factor in the hierarchical model).

2. In the second stage, we apply regression trees and boosting to identify which are the school level characteristics related to school value-added (estimated at first stage), how they are related with the outcome and how they interact among each other.

The set of analytical tools that we use to examine these issues is new to the literature, but is quickly gaining in popularity. Tree-based methods can be classified as a Machine Learning (ML) approach. The main difference between statistical and ML approaches is that while the former starts by assuming an appropriate data model and then estimates the parameters from the data, the latter avoids starting with a data model and rather uses an algorithm to learn the relationships between the response and the predictors (in our setting, students' test scores and their determinants, respectively). Furthermore, ML approach assumes that the data-generating process is complex and unknown and tries to identify the dominant patterns by observing inputs and the responses (see [9]).

Tree-based methods (extended to accommodate the multilevel context) fit the problem in hand well for several reasons. First of all, this methodology takes into account the hierarchical structure of data. The two levels of analysis are students (level 1) that are nested within schools (level 2) and it is worth disentangling the portions of variability explained at each level. Multilevel models are well suited to this. Secondly, our tree-based methodology does not force any particular functional form on the input-output relationship, and it allows for interactions among the predictors. This point is essential because the functional form of the relationships between the covariates and the outcome is unknown a priori and forcing it to be linear can considerably bias the results and, critically, it does not allow discovery of the most likely relationships between the variables. Moreover, there are reasons to believe that the educational context is intrinsically characterised by interactions among variables, since inputs are various and coexist in the same environment. So, tree-based models, that are 
able to let the variables interact and that identify which interactions are relevant in influencing the outcome, are definitely attractive (see [23]). Thirdly, the method allows a clear graphical representation of the results that helps in communicating them to policy practitioners. Alongside the deep interrogation of interactive effects, we consider this to be a major benefit of this approach.

The remainder of the paper is organised as follows: in Section 2 we review the existing literature and, in so doing, motivate our model choice; in Section 3 we present the PISA dataset and the countries that we analyse; Section 4 discusses the methodological approach (multilevel trees and boosting); in Section 5 we report the results and in Section 6 we derive conclusions and policy implications ${ }^{1}$.

\section{Background and previous literature}

In recent decades, many researchers have studied the determinants of student achievement, in order to develop policy implications aimed at improving educational systems across the world. The statistical methods proposed by the literature in this perspective are various - including linear regression, multilevel linear models and stochastic frontier analysis - in each case aimed at parameterising the educational production function (EPF). While a complete literature review of previous studies that use a EPF approach is beyond the scope of this paper, we report important points from existing contributions that can be considered as relevant for interpreting our approach. Specifically, we focus on those studies which adopt a cross-national perspective in modelling the determinants of students' educational performance by means of economic models and statistical and econometric empirical tools. Indeed, our main contribution to the academic literature stems from the relevance of the innovations brought by the ML strategy to explore differences in educational production across countries.

The Programme for International Student Assessment (PISA) was initiated by the OECD, and has been running since 2000. It involves standardised testing of 15 year olds across a large number of countries. Over the 15 years for which data are now available, PISA results have revealed that there are big discrepancies across education systems. The data allow direct comparisons of student performance in science, reading and mathematics, leading to a ranking of the countries and identifying those that score the best results (see [24]). PISA2015 data, for example, show that Singapore achieves the best results in the scientific area, followed by Japan, Estonia, Finland and Canada. For our purposes, the most interesting aspect of the PISA data is the possibility that they offer to compare the marginal effects of student and school levels variables on students' performance. Gender, immigrant status, socio-economic status (SES), proportion of disadvantaged students, school size and characteristics of the school principal are all variables that have been found to be very important in some countries but less so in others (see [26] and [38]). For example, in almost

\footnotetext{
${ }^{1}$ All analysis undertaken in this paper is conducted using the statistical software R (see $[29])$.
} 
all countries boys perform on average better than girls in the scientific subjects, with the notable exception of Finland, where girls have on average higher results than boys. As another example, after accounting for socio-economical status, immigrant students have a double probability compared to their not immigrant counterparts to achieve low results in scientific subjects (see [27]). Focusing on mathematics, four Asian countries outperform all other economies - Singapore, Hong Kong (China), Macao (China) and Chinese Taipei - and Japan is the strongest performer among all the OECD countries.

Policy responses to internationally reported PISA results have differed among participating countries. For example, in some country groups PISA deficits have been associated with a push towards more centralised control, while others have responded with much more focused reforms implemented with the specific aim of raising PISA (or similar) test scores over time (see [42]).

What is clear to experts and analysts worldwide, therefore, is that the educational systems, in their structural, internal complexity and in their various aspects, vary within and across countries. Different variables play a role and sometimes with different impacts in influencing educational results in different contexts. Analysing international datasets like PISA therefore calls for the use of a flexible model, able to identify the significant variables within each system and to fit data with different patterns. Indeed, imposing the same coefficient on the correlation between covariates and educational results in all countries is inappropriate and even the inclusion of country fixed-effects - shifting only the intercept - is not obviously an adequate solution. Therefore, it is necessary to employ more flexible instruments for the analysis of patterns that go beyond the simply "fixed-effects" which impose homogeneity of the interactions between key variables within countries.

The EPF literature builds upon the work of Coleman, Hanushek, and others by viewing education as a process in which students' performance or output (attainment or years of schooling completed) is produced from inputs including school resources, teacher quality, family attributes, and peer quality. Because outcomes cannot be changed by fiat, policy attention has focused on inputs. These include inputs that are both directly controlled by policymakers (characteristics of schools, teachers, curricula, etc.) and those that are not so controlled (family, friends, the learning capacities of the student, etc.) (see [14]). While a large part of the effect on students' attainments is due to these "uncontrolled" characetristics of students (see [7]), many researchers have found that schools' and teachers' characteristics are also of importance in determining outcomes (see, for example, [15], [3], [32] and [43]).

In this paper, we try to find out which are the inputs that are related with students' performances (output) and in our perspective, three main points need to be taken into account when modelling the educational production functions:

- Data levels of grouping: educational data have a hierarchical structure and it is important to distinguish and disentangle the portion of variability in student achievements due to different levels of grouping ( between and within classes and schools). 
- Realistic assumptions: since the educational system is a complex and unknown process, the model assumptions are a sensitive issue and are one of the main weak points of the parametric approaches to the problem. Most of the statistical approaches force the data to be explained through a functional form chosen a priori, but the imposition of such a functional form may be inappropriate - either because it does not reflect the underlying technology in some contexts (countries) or, even in none. Therefore, there is the need of a flexible approach that does not force any functional relationships among the variables, where the functional form is not known and that admits the eventuality that the relationship between a covariate (for instance, school resources) and educational results (for example, students' test scores) may be non linear.

- Interactions: interactions between cofactors (both within and between levels) are inevitable, as, for example, the relationship between average socioeconomic status of students and class/school size. In such a perspective, modelling the educational production function would require the inclusion of interaction factors that better describe how covariates combine to influence educational performances.

Most of the classical statistical techniques used in the literature to model educational data do not fulfill these requirements.

From a modelling point of view, the application of hierarchical models to educational data is straightforward. Raudenbush (see [31]) explains the advantages of applying these models in an educational context. He states that two primary goals have motivated application of hierarchical linear models in education: first, researchers have used data from many groups to strengthen estimation of random effects for each group, and the second goal is improved inference about the fixed effects. The application of hierarchical linear modelling enables researchers to go beyond the classical questions, such as why do some schools have higher achievement than others, to ask about why structural relationships vary across groups. These models also offer advantages in dealing with aggregation bias long associated with nested data structure.

For these reasons, multilevel approaches have been broadly applied in the literature. Raudenbush himself applies hierarchical models in various educational studies (see for example [6], [41] and [30]). Other examples are given by Agasisti et al. (see [1]), Masci et al. (see [21] and [22]), Plewis (see [28]) and Rumberger (see [33]), that apply multilevel linear models considering different levels of grouping, such as class, school, Local Education Authority (LEA) or geographical regions. Even where these approaches do indeed model the hierarchical structure of data, however, they still force the covariates to have a linear relationship with the outputs, without allowing possible heterogeneous interactions among the predictors.

The innovation of the present paper involves the combination of the EPF approach with a multilevel approach to estimation using a machine learning (ML) method. This allows us to relax the parametric assumptions and to discover 
the data generating process that lies behind our data. The fundamental insight behind ML approaches is as much statistical as computational and its success is largely due to its ability to discover complex structure that does not need to be imposed by the researcher in advance. It manages to find complex and very flexible functional forms in the data without simply overfitting: it finds functions that work well out-of-sample (see [23]).

Spurred by the need to relax the parametric assumptions and to explain complex systems, some researchers have already adopted a ML approach for studying some key economic and social relevant issues. Varian (see [40]) states that

"conventional statistical and econometric techniques such as regression often work well, but there are issues unique to big datasets that may require different tools. First, the sheer size of the data involved may require more powerful data manipulation tools. Second, we may have more potential predictors than appropriate for estimation, so we need to do some kind of variable selection. Third, large datasets may allow for more flexible relationships than simple linear models. Machine learning techniques such as decision trees, support vector machines, neural nets, deep learning, and so on may allow for more effective ways to model complex relationships."

Various studies on the comparison of the performance of regression and classification trees and conventional statistical methods have already been done: Fitzpatrick \& Mues (see [10]), for example, apply different modelling approaches for future mortgage default status and they show that boosted regression trees significantly outperform logistic regression. Savona (see [34]) realizes an early warning system for hedge funds based on specific red flags that help detect the symptoms of impending extreme negative returns and the contagion effect. He uses regression tree analysis to identify a series of splitting rules that act as risk signals and he compares these results with the ones obtained applying logistic regression, showing that they are consistent.

Our paper is not the first in which regression trees have been applied in an educational context. Thomas \& Galambos (see [39]) apply regression and decision trees to investigate how students' characteristics and experiences affect satisfaction. The data mining approach is able to identify the specific aspects of students' university experience that most influence students' satisfaction, in a survey of students in Iowa city (IA). Ma (see [19]) analyses students' performances at middle and high schools employing a two-stage analysis, the first stage of which involves estimation of the rate of growth in mathematics achievements of each student, by means of a hierarchical linear model (HML), while the second stage applies classification and regression trees (CART) to students' characteristics. Cortez \& Silva (see [8]) apply some Data Mining (DM) methods such as regression trees and random forests to relate Portuguese secondary school students' scores in mathematics and reading to students' characteristics. Grayson (see [13]) merges results of students at York University in Toronto that were surveyed at the end of the first year with information on grades from administrative records, by means of regression trees. 
In this paper, we relax the assumption of linear effects of student-level covariates on their performance, instead modelling this relationship by means of flexible regression trees. In the first stage of the analysis, we therefore combine multilevel models with regression trees. In the second stage, when exploring the factors associated to the school value-added, we again employ regression trees, combining this method with a boosting procedure, so gaining more precise estimates of determinants of school performance. This type of research is very much in its infancy. We are aware of only one other study [12] - conducted concurrently with and independently of the present research - that uses regression trees in an education context. That study also draws on PISA data, but focuses specifically on mathematics achievement in Australia.

\section{The Dataset}

The Programme for International Student Assessment (PISA) data assesses student performance, on a triennial basis, in science, mathematics, reading, collaborative problem solving and financial literacy. In our analysis, we use PISA data for 2015, focusing on 9 countries: Australia, Canada, France, Germany, Italy, Japan, Spain, UK and USA. The selection of countries is motivated by the attempt of representing different "types" of educational systems: AngloSaxon, Asian, Continental-Europe and Southern Europe. Future research will be realized to extend the analysis to other educational regimes, such as Nordic countries, South America and Africa. We also need to keep the number of countries quite limited, for favoring easy interpretation of results and their comparison. PISA requires both students and school principals to compile a questionnaire. We therefore have information both at student and school levels. The school questionnaire contains around 30 multiple choice questions about (i) school background information, (ii) school management, (iii) teaching staff, (iv) assessment and evaluation, (v) targeted groups (eg how schools might organise instruction differently for students with different abilities) and (vi) school climate. Meanwhile the student questionnaire contains around 50 multiple choice questions about the (i) student, student's family and student's home (home resources, parents support), (ii) student's view about his/her life (anxiety, effort, collaboration, perception of school climate), (iii) student's school, (iv) student's school schedule and learning time and (v) student's view on science. In addition, students are required to undertake tests in several subjects, and, upon completion, is awarded ten scores for each subject, measuring different abilities within each subject. For example, in science, these scores measure students' ability to explain phenomena scientifically, to evaluate and design scientific enquiry, and to interpret data and evidence scientifically; in reading, they measure student's ability in retrieving information, forming a broad understanding, developing an interpretation, reflecting on and evaluating the content of a text, reflecting on and evaluating the form of a text, etc.; and in mathematics, they measure students' ability in identifying the mathematical aspects of a problem situated in a real-world context and identifying the significant variables, recognising mathe- 
matical structure (including regularities, relationships and patterns) in problems or situations, simplifying a situation or problem in order to make it amenable to mathematical analysis and so on. The ten scores are very highly correlated within each subject (coefficient of correlation $\simeq 0.8 / 0.9$ ). In each country, test scores have been standardised in order to have mean $=500$ and standard deviation $=100$. Some other variables, noted in the following tables, are indicators built by PISA and have been standardised so that the mean $=0$ and standard deviation $=1$. An example is ESCS, which is a weighted average of measures of parental education, wealth, home educational resources and cultural possessions. In our analysis, we focus on mathematics test scores, choosing just one of the ten scores (the same one for each country) as answer variable. We report in Tables 1 and 2 the variables used in our two-stage analysis, with full definitions ${ }^{2}$.

\footnotetext{
${ }^{2}$ We report here the students' score in mathematics, since this will be our response variable in the model. We do not consider students' scores in other educational subjects in the analysis. In order to have a complete overview of the data collected by PISA, refer to the PISA 2015 technical report in http://www.oecd.org/pisa/data/2015-technical-report/.
} 


\begin{tabular}{|c|c|c|}
\hline Variable name & Type & Explanation \\
\hline MATH SCORE & num & $\begin{array}{l}\text { Mathematics PISA test score } \\
(\text { mean }=0, \mathrm{sd}=1)\end{array}$ \\
\hline GENDER & $0 / 1$ & $\begin{array}{l}0=\text { male } \\
1=\text { female }\end{array}$ \\
\hline ESCS & num & $\begin{array}{l}\text { Socio-economical status } \\
(\text { mean }=0, \mathrm{sd}=1)\end{array}$ \\
\hline IMMIGRANT & cat & $\begin{array}{l}0=\text { not immigrant student } \\
1=\text { first generation immigrant } \\
2=\text { second generation immigrant }\end{array}$ \\
\hline TIME HOMEWORK & int & $\begin{array}{l}\text { Number of hours of student } \\
\text { homework per week }\end{array}$ \\
\hline HISCED & cat & $\begin{array}{l}\text { Highest level of education of parents } \\
\text { (levels from } 0 \text { to } 6 \text { ) }\end{array}$ \\
\hline VIDEO GAME & $0 / 1$ & $\begin{array}{l}\text { Whether the student plays video games } \\
\text { or not }\end{array}$ \\
\hline SPORT & $0 / 1$ & Whether the student plays sport or not \\
\hline DISCIPLIN CLIMATE & num & How is the disciplinary climate in class \\
\hline TEACHER SUPPORT & num & Teacher support in class \\
\hline MMINS & num & Hours of mathematics lessons per week \\
\hline BELONG & num & $\begin{array}{l}\text { Subjective well-being: } \\
\text { sense of belonging to school }\end{array}$ \\
\hline MOTIVAT & num & $\begin{array}{l}\text { Student Attitudes, Preferences and } \\
\text { Self-related beliefs: Achieving motivation }\end{array}$ \\
\hline ANXTEST & num & Personality: test anxiety \\
\hline COOPERATE & num & $\begin{array}{l}\text { Collaboration and teamwork dispositions: } \\
\text { Enjoy cooperation }\end{array}$ \\
\hline PARENTS SUPPORT & num & Parents emotional support \\
\hline CULTURAL POSSESSION & num & Cultural possession at home \\
\hline HOME EDUCAT RESOURC & num & Home educational resources \\
\hline
\end{tabular}

Table 1: List of student level variables of PISA2015 survey used in the analysis, with the relative explanations. Note: we report here only the test score in mathematics that we use as answer variable in the first stage of the analysis. In each country, we standardize the test score in order to have mean $=0$ and sd $=1$. All variables from "DISCIPLIN CLIMATE" to the end are indicators built by PISA and have mean $=0$ and $\mathrm{sd}=1$. 


\begin{tabular}{|c|c|c|}
\hline Variable name & Type & Explanation \\
\hline \# STUDENTS & num & Number of students in the school \\
\hline RATIO-COMPUTER-STUD & num & $\begin{array}{l}\text { Number of available computers } \\
\text { per student }\end{array}$ \\
\hline MANAGEMENT1 & $1 / 6$ & $\begin{array}{l}\text { How much the school principal uses } \\
\text { student performance results to develop } \\
\text { school's educational goals }\end{array}$ \\
\hline MANAGEMENT2 & $1 / 6$ & $\begin{array}{l}\text { How much the school principal discusses } \\
\text { schools' academic goals with teachers } \\
\text { at faculty meetings }\end{array}$ \\
\hline STUD-ADMIT-RECORD & $0 / 1$ & $\begin{array}{l}\text { Whether the students are admitted } \\
\text { to the school depending on their } \\
\text { previous scores or not }\end{array}$ \\
\hline PRIVATE & $0 / 1$ & $\begin{array}{l}0=\text { Public school } \\
1=\text { Private school }\end{array}$ \\
\hline \% GOVERN FUNDS & num & $\begin{array}{l}\text { Percentage of school funds } \\
\text { given by the government }\end{array}$ \\
\hline TEACHERS-INADEQ & $1 / 4$ & $\begin{array}{l}\text { How much the principal thinks that } \\
\text { teachers are inadequate (on a } 1 \text { to } 4 \text { scale) }\end{array}$ \\
\hline MATERIALS-INADEQ & $1 / 4$ & $\begin{array}{l}\text { How much the principal thinks that } \\
\text { materials are inadequate (on a } 1 \text { to } 4 \text { scale) }\end{array}$ \\
\hline INFRASTRUCT-INADEQ & $1 / 4$ & $\begin{array}{l}\text { How much the principal thinks that } \\
\text { infrastructures are inadequate } \\
\text { (on a } 1 \text { to } 4 \text { scale) }\end{array}$ \\
\hline RATIO-STUDENTS-TEACHER & num & Student-teacher ratio \\
\hline RATIO-STUDENTS-TEACHER5 & num & Student-teacher with level 5 ratio \\
\hline \% STUD SPECIAL NEEDS & num & Proportion of students with special needs \\
\hline \% DISADVANT STUDENTS & num & $\begin{array}{l}\text { Proportion of disadvantaged students } \\
\text { in terms of socio-economical index }\end{array}$ \\
\hline STUDENTS TRUANCY & $1 / 4$ & Students truancy (on a 1 to 4 scale) \\
\hline STUD-NO-RESPECT-TEACH & $1 / 4$ & $\begin{array}{l}\text { Students lack respect for teachers } \\
\text { (on a } 1 \text { to } 4 \text { scale) }\end{array}$ \\
\hline TEACHER ABSENTEEISM & $1 / 4$ & Teacher absenteeism (on a 1 to 4 scale) \\
\hline \% PARENTS SPEAK TEACHERS & num & $\begin{array}{l}\text { Proportion of students' parents } \\
\text { speaking with teachers at the meeting }\end{array}$ \\
\hline \% PARENTS IN SCHOOL GOVERN & num & $\begin{array}{l}\text { Proportion of students' parents } \\
\text { participating at the school government }\end{array}$ \\
\hline
\end{tabular}

Table 2: List of school level variables of PISA2015 survey used in the analysis, with the relative explanations. Note: all variables of type $n_{1} / n_{2}$ assume integer values ranging from $n_{1}$ to $n_{2}$, with the maximum value corresponding to $n_{2}$.

Table 3 reports the sample size in the different countries, specifying the number of students and the number of schools that participated in the PISA survey. 
The sample sizes vary somewhat across countries, but we have chosen the countries used in our analysis so as to ensure that there are sufficient observations in each to allow robust conclusions to be drawn.

Lastly, it is worth noting that the percentage of missing data at student level is very low (about 2 to $5 \%$ among countries), while at school level it is slightly higher (about 10 to $25 \%$ among countries). We note, however, that a major advantage of tree-based algorithms concerns their performance in the presence of missing data - see for example [5] and [18].

\begin{tabular}{lll}
\hline \hline Country & \# Students & \# Schools \\
\hline Australia & 14,530 & 758 \\
Canada & 20,058 & 759 \\
France & 6,108 & 252 \\
Germany & 6,504 & 256 \\
Italy & 11,583 & 474 \\
Japan & 6,647 & 198 \\
Spain & 6,736 & 201 \\
UK & 14,157 & 550 \\
USA & 5,712 & 177 \\
\hline \hline
\end{tabular}

Table 3: Sample size in the 9 selected countries.

\section{Methodology}

We develop and employ a two-stage procedure. In the first stage, we apply a mixed-effects regression tree (RE-EM tree), with only random intercept, in which we consider two levels of grouping: students (level 1) nested within schools (level 2). The response variable of the mixed-effects model is the student PISA test score in maths, this being regressed against a set of student level characteristics (fixed coefficients), plus a random intercept that describes the school effect. By means of this model, we can both estimate the fixed coefficients of the student level predictors on the outcome and the school value-added (corresponding to the random intercept). In the second stage, we regress the estimated school value-added against a set of school level characteristics, by means of regression trees and boosting.

\subsection{An introduction to tree-based methods}

Given an outcome variable and a set of predictors, tree-based methods for regression (see [17]) involve a segmentation or stratification of the predictors space into a number of regions. In order to make a prediction for a given observation, we typically use the mean of the observations in the region to which it belongs. Building a regression tree involves two steps: 
1. We divide the predictor space - that is, the set of possible values for $X_{1}, X_{2} \ldots, X_{p}$ - into $\mathrm{J}$ distinct and non-overlapping regions, $R_{1}, R_{2} \ldots, R_{J}$. For simplicity, we consider these regions as high-dimensional rectangles (or boxes);

2. For every observation that falls into the region $R_{j}$, we make the same prediction, which is the mean of the response values for the observations in $R_{j}$.

The regions are chosen in order to minimize the Residual Sum of Squares (RSS):

$$
\sum_{j=1}^{J} \sum_{i \in R_{j}}\left(y_{i j}-\hat{y}_{R_{j}}\right)^{2}
$$

where $\hat{y}_{R_{j}}$ is the mean of the observations within the $\mathrm{j}$-th box and $y_{i j}$ is the $\mathrm{i}$-th observation within the $\mathrm{j}$-th box.

It is useful to contrast this approach with the more conventional methods typically used in the education economics literature - namely a linear functional form imposed on the education production function. In particular, a linear regression model assumes the following functional form:

$$
f(X)=\beta_{0}+\sum_{j=1}^{p} X_{j} \beta_{j} ;
$$

(where $\mathrm{p}$ is the number of predictors) whereas regression trees assume a model of the form:

$$
f(X)=\sum_{m=1}^{M} c_{m} I_{\left(X \in R_{m}\right)}
$$

where $\mathrm{M}$ is the total number of distinct regions and $R_{1}, \ldots, R_{M}$ represent the partition of feature space.

Determining which model is more appropriate depends on the problem: if the relationship among the features and the response is well approximated by a linear model, then an approach such as linear regression will likely work well, and will outperform a method such as a regression tree that does not exploit this linear structure (see [40]). If instead there is a highly non-linear and complex relationship between the features and the response, then decision trees may outperform classical approaches. The complex nature of educational production renders this an ideal candidate for exploring the ability of trees-based methods to interrogate non-linearities and interactions in the data.

In order to give an example of how to read the result of a regression tree, let us imagine that we want to regress stadardised student test scores (that is a continuous variable with mean $=0$ and standard deviation $=1$ ) against three covariates: Economic Social and Cultural Status (ESCS, an indicator of socio-economic status defined to be a continuous variable with mean $=0$ and 
standard deviation $=1$ ), number of siblings (variable assuming integer values) and time spent on homework (variable assuming integer values) and that Figure 1 reports the result of the regression.

Outcome variable: Student test score
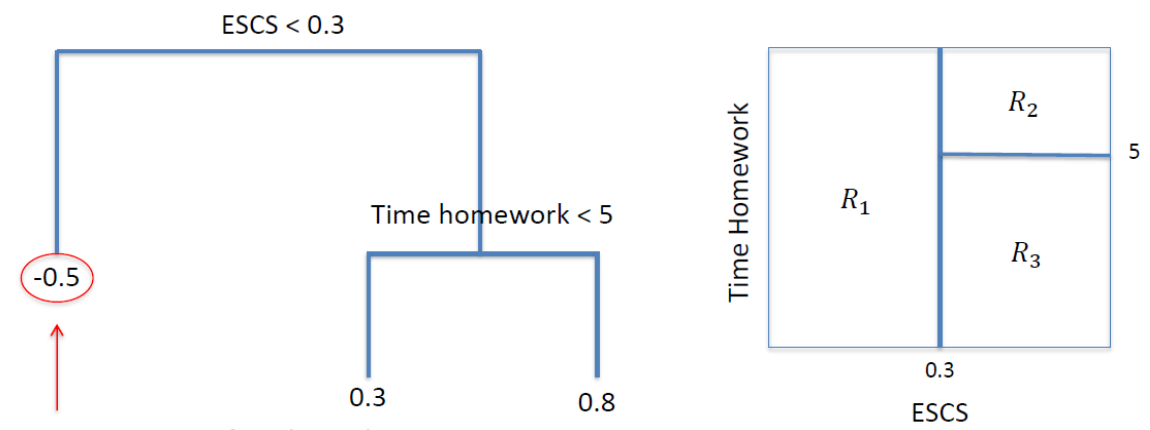

Average score of students that

are in this branch

Figure 1: Example of the result of a regression tree. The answer variable is students' tests scores (continuous variable with mean $=0$ and $\mathrm{sd}=1$ ) and the three covariates are: (i) socioeconomic index (ESCS, continuous variable with mean $=0$ and sd $=1$ ), (ii) number of siblings (integer variable) and (iii) time of homework (integer variable counting the hours of homework at home). The image on the left represents the partition of the covariate space into three regions, computed by the regression tree. The image on the right represents the regression tree. Variable "number of siblings" does not appear in either the two images, since it does not result to be statistically relevant.

First, we notice that the number of siblings does not appear in the tree. This means that this variable is not able to catch any variability in students' test scores and therefore, the tree excludes it from the splits. When reading the tree, every time the condition at the split point is satisfied, we follow the left branch, otherwise, we follow the one on the right. On the left side of the figure, we see the regression tree while on the right, we see the partition of the covariate space into three regions. The most important variable turns out to be ESCS: a student with an ESCS less than 0.3 follows the left branch yielding a predicted student test score of -0.3 ; instead, if the student's ESCS exceeds 0.3, he/she goes in the right branch and, at this point, if he/she studies less than 5 hours per week, his/her predicted score is 0.3 , while if he/she studies more, it is 0.8 . The algorithm itself identifies the threshold values in order to minimize the Residual Sum of Squares (RSS). Focusing on the interaction between the two covariates, it is noteworthy that the variable "time of homework" matters if the ESCS is higher than 0.3, while it is irrelevant if the ESCS is lower than 0.3.

This brief and simplified explanation serves as a foundation for the methods that we discuss in the following two subsections: RE-EM trees and Boosting, 
which are the ones used in the empirical analysis of this paper.

\subsection{Multilevel models and RE-EM trees}

RE-EM trees (see [36]) work in a similar fashion to random effects (or multilevel) linear models (see [37]) but relax the linearity assumptions of the fixed covariates with the response. Given $N=\sum_{j=1}^{J} n_{j}$ individuals, nested within J groups, a two-level linear model takes the form:

$$
y_{i j}=\beta_{0}+\sum_{k=1}^{p} \beta_{k} x_{k i j}+b_{j}+\epsilon_{i j}
$$

where

$i=1, \ldots, N$ is the index of the $\mathrm{i}$-th individual;

$j=1, \ldots, J$ is the index of the $\mathrm{j}$-th group;

$y_{i j}$ is the answer variable of the individual i within group $\mathrm{j}$;

$\boldsymbol{\beta}$ is the $(\mathrm{p}+1)$-dimensional vector of fixed coefficients;

$x_{1 i j}, \ldots, x_{p i j}$ are the $\mathrm{p}$ (fixed) predictors;

$b_{j}$ is the (random) effect of the group $\mathrm{j}$ on the answer variable (value-added of group $\mathrm{j}$ )

and $\epsilon$ is the vector of the residuals.

Both $\mathbf{b}$ and $\boldsymbol{\epsilon}$ are assumed to be normally distributed with mean 0 and variance $\sigma_{b}^{2}$ and $\sigma_{\epsilon}^{2}$ respectively. The vector of fixed coefficients $\boldsymbol{\beta}$ is the same for all the $\mathbf{J}$ groups, while the random intercept $b_{j}$ changes across groups $\left(b_{j}\right.$ is the value-added, positive or negative, of the $\mathrm{j}$-th group). The larger is $\sigma_{b}^{2}$ the larger are the differences across groups.

RE-EM trees merge multilevel models with regression trees, substituting the linear regression of the fixed covariates with a regression tree. So, in place of a linear regression, a regression tree is built to model the relationship between the output (test scores) and the inputs (student characteristics). In our case, the individuals are the students and the groups are the schools. If we consider students (level 1) nested within schools (level 2), the two-levels model (with only random intercept), for pupil $i, i=1, \ldots, n_{j}, n=\sum_{j} n_{j}$, in school $j, j=1, \ldots, J$ takes the form:

$$
y_{i j}=f\left(x_{i j 1}, \ldots, x_{i j p}\right)+b_{j}+\epsilon_{i j}
$$

with

$$
\begin{aligned}
& b \sim N\left(0, \sigma_{b}^{2}\right), \\
& \epsilon \sim N\left(0, \sigma_{\epsilon}^{2}\right)
\end{aligned}
$$


where $\mathrm{f}(\mathrm{X})$ takes the form in (3) and

$y_{i j}$ is the maths PISA test score of student $\mathrm{i}$ within school $\mathrm{j}$;

$x_{i j 1}, \ldots, x_{i j p}$ are the p-predictors at student level;

$b_{j}$ is the random effect of school $\mathbf{j}$, which in this paper is interpreted as a school-specific value-added (VA) to the educational performance of the student; and

$\epsilon_{i j}$ is the error.

It is generally assumed that the errors $\epsilon$ are independent across objects and are uncorrelated with the effects $b$. Note, however, that autocorrelation structure within the errors for a particular object is allowed; to do this, we allow the variance/covariance matrix of errors to be a non-diagonal matrix. The random effect $b_{j}$ is still linear with the outcome, while the fixed covariates, that do not change across groups (schools) are related to the outcome by means of a regression tree.

Moreover, one of the advantages of multilevel models is that we can compute the Proportion of Variability explained by Random Effects (PVRE):

$$
P V R E=\frac{\sigma_{b}^{2}}{\sigma_{b}^{2}+\sigma_{\epsilon}^{2}}
$$

PVRE measures how much of the variability of test scores can be attributed to students' characteristics or to structural differences across schools - in other words, PVRE disentangles the variability of test scores between students from that between schools. Applying RE-EM trees to data of each of the 9 countries, we can both (i) analyse which are the student level variables that are related with students' achievements and in which way and (ii) estimate the school valueadded (random effect $b_{j}$ ) to students' achievements and compute the proportion of student scores' variability given by differences across schools (PVRE). With the aim of adequatly considering the structural differences between countries, we estimate the educational production function as specified in the equation (5) separately for each country.

\subsection{Regression trees and Boosting}

Regression trees have a series of advantages: they do not force any functional relationship between the response variable and the covariates; they can be displayed graphically and are easily interpretable; they can handle qualitative predictors; they allow interactions among the variables and they can handle missing data. Nevertheless, they suffer from high variance in the estimation of the relationship between covariates and test scores and they are sensitive to outliers. For these reasons, methods have been developed that serve to reduce variance and increase predictive power; these include bagging, random forests and boosting (see [17]).

Boosting (see [9]) is a method for improving model accuracy, based on the idea that it is easier to find and average many rough rules of thumb, than to find a single, highly accurate prediction rule (see [35]). Related techniques - 
including bagging, stacking and model averaging - also build and merge results from multiple models, but boosting is unique amongst these in that it is sequential: it is a forward, stagewise procedure. In boosting, models (e.g. regression trees) are fitted iteratively to the data, using appropriate methods gradually to increase emphasis on observations that are modelled poorly by the existing collection of trees. Boosting algorithms vary in exactly how they quantify lack of fit and select settings for the next iteration. In the context of regression trees and for regression problems, boosting is a form of "functional gradient descent". Consider a loss function - in this case, a measure (such as deviance) that represents the loss in predictive performance of the educational production function due to a suboptimal model. Boosting is a numerical optimisation technique for minimising the loss function by adding, at each step, a new tree that is chosen from the available trees on the basis that it most reduces the loss function. In applying the Boosting Regression Tree (BRT) method, the first regression tree is the one that, for the selected tree size, maximally reduces the loss function. For each subsequent step, the focus is on the residuals: on variation in the response that is not so far explained by the model. For example, at the second step, a tree is fitted to the residuals of the first tree, and that second tree could contain quite different variables and split points compared with the first. The model is then updated to contain two trees (two terms), and the residuals from this two-term model are calculated, and so on. The process is stagewise (not stepwise), meaning that existing trees are left unchanged as the model is enlarged. The final BRT model is then a linear combination of many trees (usually hundreds or thousands) that can be thought of as a regression model where each term is a tree. A number of parameters control the model-building process: the learning rate $(l r)$, that drives the velocity with which the tree is learning, that is, it shrinks the contribution of each tree; the maximum number of trees to be considered; the distribution of response variable; and the tree complexity $(t c)$, that is the maximum level of interaction among variables (see [9]).

The increase in predictive power obtained by adopting a BRT approach comes at a cost in terms of ease of interpretation. Indeed, with boosting it is no longer possible to display the tree graphically. But the results can nonetheless be represented quite simply. BRT provides a ranking of the variables, based on their ability to reduce the node purity in the tree (see [4]), that is the significance of each variable. In order to measure the marginal impact of each predictor, Friedman (see [11]) has proposed the use of partial dependence plots. These plots are based on the following idea: consider an arbitrary model obtained by fitting a particular structure (e.g., random forest, support vector machine, or linear regression model) to a given dataset. This dataset includes $\mathrm{N}$ observations $y_{k}$ of a response variable $y$, for $k=1,2, \ldots, N$, along with $p$ covariates denoted $x_{i k}$ for $i=1,2, \ldots, p$ and $k=1,2, \ldots, N$. The model generates predictions of the form:

$$
\hat{y}_{k}=F\left(x_{1 k}, x_{2 k}, \ldots, x_{p k}\right)
$$

for some mathematical function $F(\ldots)$. In the case of a single covariate $x_{j}$, 
Friedman's partial dependence plots are obtained by computing the following average and plotting it over a useful range of $x$ values:

$$
\Phi_{j}(x)=\frac{1}{N} \sum_{k=1}^{N} F\left(x_{1, k}, \ldots, x_{j-1, k}, x, x_{j+1, k}, \ldots, x_{p, k}\right)
$$

The idea is that the function $\Phi_{j}(x)$ tells us how the value of the variable $x_{j}$ influences the model predictions $\hat{y}$ after we have "averaged out" the influence of all other variables.

It is possible to visualise also the joint effect of two predictors on the response variable. The multivariate extension of the partial dependence plots just described is straightforward: the bivariate partial dependence function $\Phi_{i, j}(x, y)$ for two covariates $x_{i}$ and $x_{j}$ is defined analogously to $\Phi_{j}(x)$ by averaging over all other covariates, and this function is still relatively easy to plot and visualise. In particular:

$$
\Phi_{i, j}(x, y)=\frac{1}{N} \sum_{k=1}^{N} F\left(x_{1, k}, \ldots, x_{i-1, k}, x, x_{i+1, k}, \ldots, x_{j-1, k}, y, x_{j+1, k}, \ldots, x_{p, k}\right)
$$

We therefore apply BRT in each country, in the second stage of our analysis, using the estimated school value-added (first stage) as response variable and a set of school-level characteristics as predictors.

\section{Results}

We begin by comparing the results of PISA test in mathematics across the 9 selected countries. Table 4 reports descriptive statistics and Figure 2 shows their distributions.

\begin{tabular}{llll}
\hline \hline Country & Mean & Median & sd \\
\hline Australia & 481.587 & 480.903 & 94.443 \\
Canada & 505.021 & 504.813 & 85.757 \\
France & 496.997 & 503.998 & 94.647 \\
Germany & 509.170 & 511.604 & 87.814 \\
Italy & 500.235 & 501.275 & 89.483 \\
Japan & 532.66 & 536.96 & 89.256 \\
Spain & 491.361 & 493.681 & 83.519 \\
UK & 490.765 & 492.591 & 85.577 \\
USA & 467.383 & 467.286 & 88.089 \\
\hline \hline
\end{tabular}

Table 4: Descriptive statistics of students' PISA2015 test scores in mathematics in the 9 selected countries. 

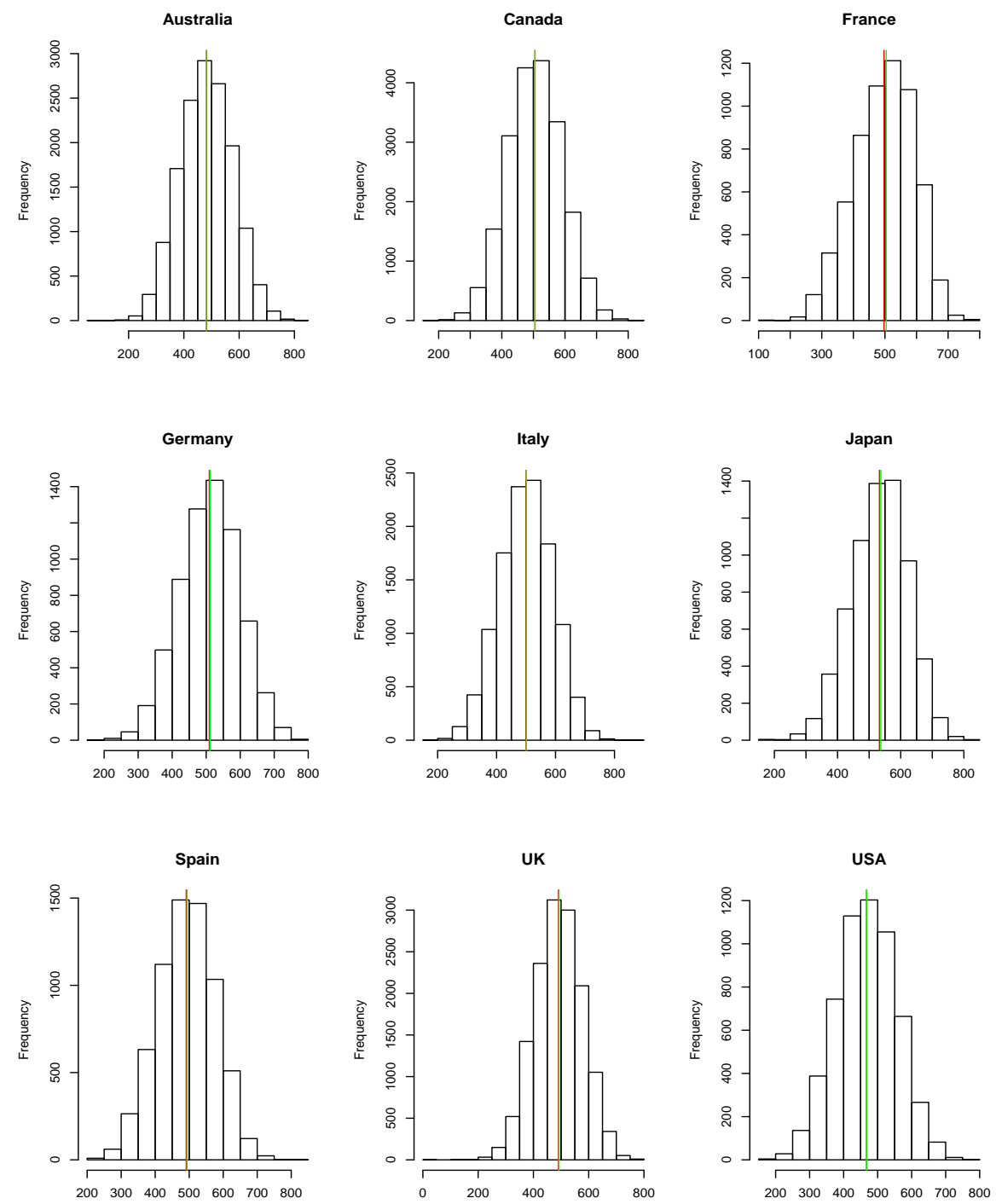

Figure 2: Histograms of PISA students test scores in mathematics in the 9 selected countries. Red line refers to the mean, green one to the median. Note: by construction, PISA test scores are standardized at the international level for having mean $=500$ and standard deviation $=100$.

Japan is the country where students, on average, perform higher test scores, followed by Germany, while USA is the country where students report the lowest scores. In almost all the countries, the mean and median are quite close, suggesting that the distributions are symmetric; France and Japan are exceptions, 
where in both cases the mean is somewhat smaller than the median, suggesting that there is a slightly higher proportion of students with relatively low test scores.

\subsection{First stage: Estimating the determinants of students' test scores and school value-added by using RE-EM trees}

RE-EM trees are fitted, separately for each country, using the standardised students' PISA test score in maths as response (in each country students' scores have been standardized, having mean 0 and standard deviation 1) and the entire set of student level variables shown in Table 1 as predictors. A random intercept is given by the grouping factor of students within schools (identified by school ID). Results of this first stage comprise the regression tree with the coefficients for the inputs of individual students' characteristics, the proportion of explained variability by the multilevel model (PV) and the PVRE, within each country.

Figure 3 shows the trees of fixed student level covariates in each country ${ }^{3}$, while Table 5 shows the estimated variance of errors, estimated variance of random effects, PV and PVRE of the RE-EM trees models.

\footnotetext{
${ }^{3}$ We only report here the figure for Australia, while the figures for other countries are reported in Appendix in Figure 7.
} 


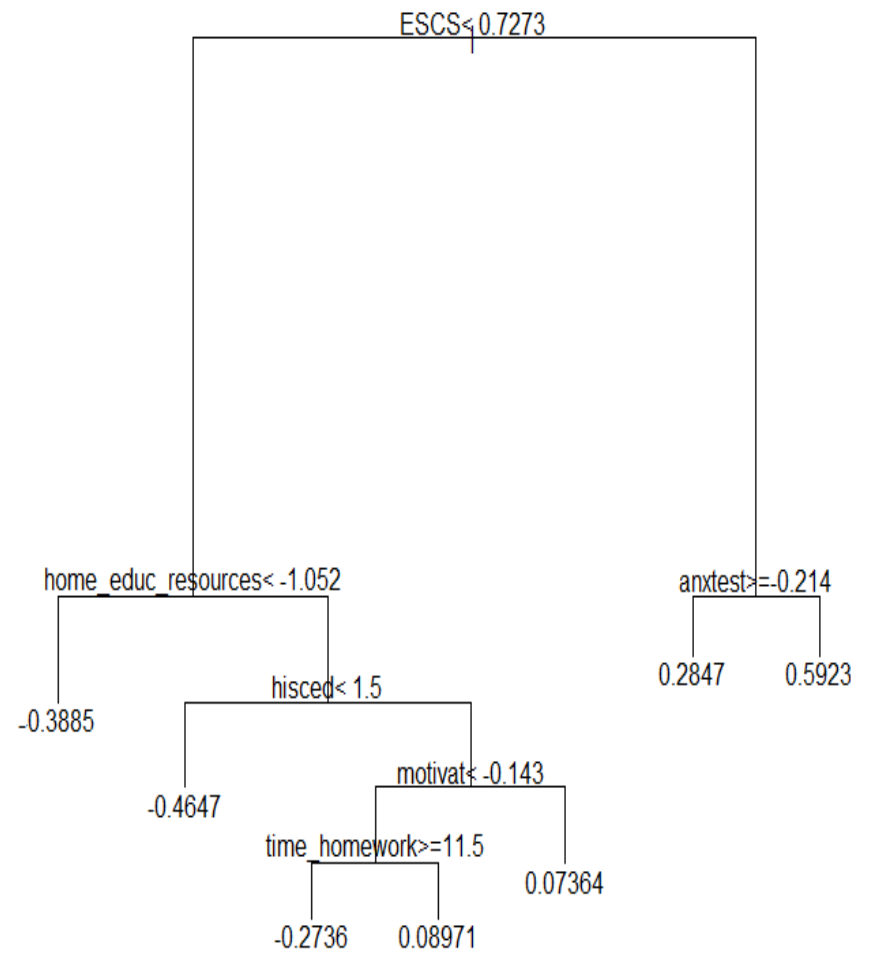

Australia

Figure 3: Fixed effect tree of first stage analysis (RE-EM tree in model 5) in Australia. 


\begin{tabular}{lllll}
\hline \hline Country & $\sigma_{\epsilon}^{2}$ & $\sigma_{b}^{2}$ & PVRE & PV \\
\hline Australia & 0.690 & 0.125 & $15.41 \%$ & $33.59 \%$ \\
Canada & 0.724 & 0.143 & $16.49 \%$ & $29.93 \%$ \\
France & 0.464 & 0.419 & $47.47 \%$ & $55.28 \%$ \\
Germany & 0.525 & 0.437 & $45.44 \%$ & $50.17 \%$ \\
Italy & 0.568 & 0.395 & $41.04 \%$ & $45.57 \%$ \\
Japan & 0.510 & 0.437 & $46.13 \%$ & $50.32 \%$ \\
Spain & 0.706 & 0.068 & $0.08 \%$ & $30.11 \%$ \\
UK & 0.695 & 0.162 & $18.97 \%$ & $32.51 \%$ \\
USA & 0.689 & 0.132 & $16.15 \%$ & $33.45 \%$ \\
\hline \hline
\end{tabular}

Table 5: RE-EM trees results in the nine selected countries.

The ability of student features to explain students' achievements varies markedly across countries. In some countries, a quite substantial proportion of the differences in students' achievements are explained by student level variables such as socio-economic index, immigrant status, anxiety in dealing with the scholastic life, self-motivation and so on. France, Japan and Germany, that have high PVs $(55.28 \%, 50.32 \%$ and $50.17 \%$ respectively), are examples of this kind. In other countries, such as Canada and Spain, it seems that these student characteristics are not sufficient to explain much of the variability in outcomes. Despite these differences, Figure 7 in Appendix shows that the impact of several types of student characteristics are coherent across countries. In almost all the countries, the grape of the most important variables includes (1) the indicator that measures students' self-reported anxiety toward tests, (2) socio-economic index (ESCS) and (3) the indicator measuring the self-reported motivation. In particular, the ESCS turns out to be the most important variable within five countries out of the nine (Australia, France, Spain, UK and USA). In Canada, Germany and Italy, the most significant variable is ANXTEST: students that feel anxious in their studies have on average lower test scores than more confident students. Japan is the only country where students' self-motivation is the most important variable: if a student has an index of self-motivation less than a certain threshold (in this case, less than -0.9017), then no other variables matter in predicting achievement; otherwise, parents' education and anxiety matter. Other recurrent variables are the highest educational level of parents (HISCED), the educational resources at home, the disciplinary climate and the number of minutes in the maths lesson. Parental education is a particularly relevant variable in Australia, Italy and Japan. Higher levels of parental education are associated with better student achievement. While in Australia and Italy, the different impact of parental education is between parents with less or more than ISCED2 (lower secondary), in Japan the difference is between students with parents with less or more than ISCED4 (post-secondary). Disciplinary climate results to be an important factor in UK and USA: apparently, students that perceive a good disciplinary climate in the class, perform on average better 
than others.

When tuning to the estimation of school value-added, it differs across countries, with some countries showing a stronger role of schools in affecting test scores than others. In France, for example, almost the 50\% (PVRE $=47.47 \%)$ of the unexplained variability among students is captured by the "school effect". This means that results of students attending different schools also differ, probably due to heterogeneity in schools' quality. By way of contrast, Spain is a country in which students' achievements are quite homogeneous across schools $($ PVRE $=0.08 \%)$. In general, schools have a clear role to play in explaining the variability of students' scores in France, Japan, Germany and Italy (about 40/45\%); in Australia, Canada, UK and the USA, a smaller - but still nonnegligible - portion of variability is explained at school level (about 15/20\%). This is a finding with very clear policy implications - policies aimed at schools (rather than, say, families) are likely to have much more potency in the former group of countries than in the latter.

Different students' achievements across schools may be the consequence of different school policy and teaching programmes or of the socio-economic composition of the school body (see [25]). While the available data and the proposed methodology do not allow investigation of the channels that drive the causal relationships between schools' characteristics and test scores, the next section uses regression trees and boosting to show correlations between schools' features and their estimated "value-added".

\subsection{Second stage: Modelling the determinants of school value-added through regression trees and boosting}

In the second stage of the analysis, we run, within each country, a regression model based on trees and boosting. The response variable is the school valueadded, as estimated at the first stage, while the predictors are the school level variables described in previous section and contained in the questionnaire filled by school principals. Figure 4 and Table 6 show the variable importance ranking within each country ${ }^{4}$ and the proportion of total variability explained by the model, respectively.

\footnotetext{
${ }^{4}$ We only report here the figure for Australia, while the figures for other countries are reported in Appendix in Figure 8.
} 
Variables importance in Australia

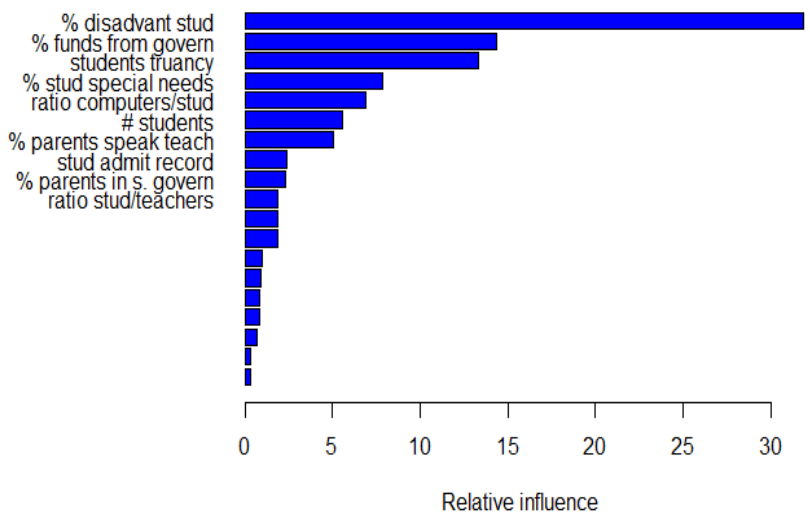

Figure 4: School level variables importance ranking in the second stage of the analysis in Australia. Boosting creates a ranking of the relative influences of the covariates on the outcome variable (school value-added). To lighten the reading, we report here only the first ten most important variables (where the most important variable is the one able to catch the bigger part of variability in the outcome).

\begin{tabular}{llllll}
\hline \hline & Australia & Canada & France & Germany & Italy \\
\hline PV & $40.36 \%$ & $28.09 \%$ & $59.13 \%$ & $53.08 \%$ & $28.09 \%$ \\
\hline & Japan & Spain & UK & USA & \\
\hline PV & $30.87 \%$ & $14.15 \%$ & $39.12 \%$ & $35.81 \%$ & \\
\hline \hline
\end{tabular}

Table 6: Proportion of explained variability (PV) of the second stage boosting model, in the 9 selected countries.

We report in the figures only the ten most important variables within each country, both because the remaining variables are statistically irrelevant and to lighten the reading. School size ("\# students"), proportion of disadvantaged students, proportion of students with special needs, students' truancy and the ratio of computers to students are typically the most important variables in each country (see Figure 8 in Appendix). This means that the school value-added is mainly associated with students' socioeconomic composition and to school size, more so than with managerial characteristics or proxies for resources, as inadequacy of materials and infrastructure. Besides these four main variables, participation of parents, measured both as proportion of parents speaking with 
teachers and participating in school governance, and the percentage of funds given by the government are also important in some countries to qualify the estimated schools' value-added.

\subsubsection{Describing the patterns of the impact of school variables on schools' value-added}

After identifying the important variables, in order to detect the magnitude and the way in which these predictors are associated with the response, we visualise in Figure 5 the partial plots of the four most significant variables within each country $^{5}$, noting that these differ across countries.

Australia
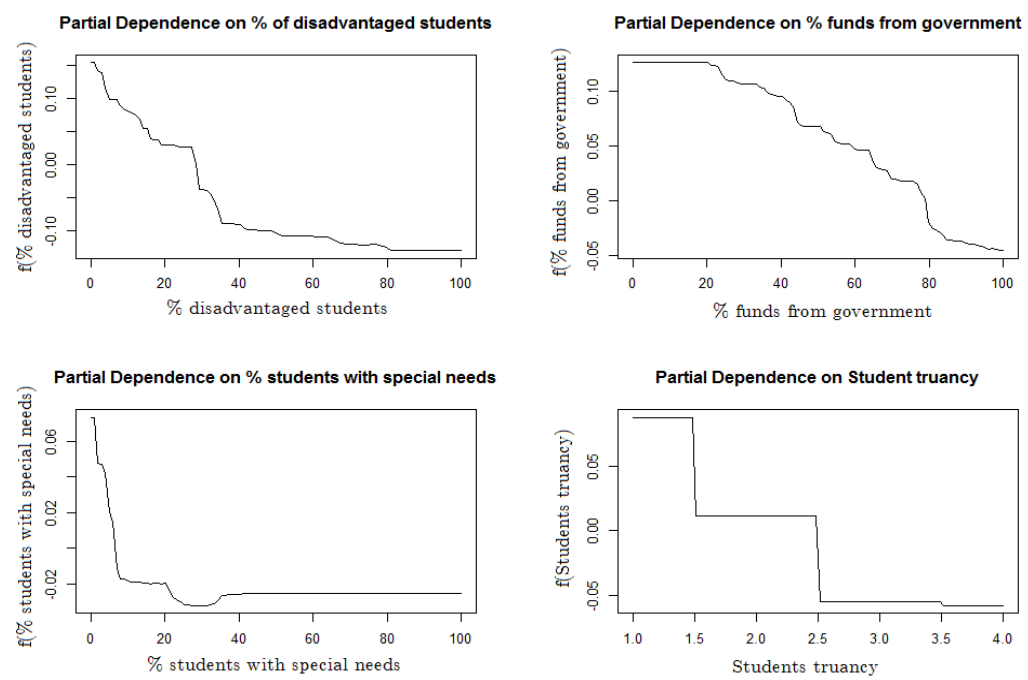

Figure 5: Partial plot of the four most important school level variables in the association with school value-added, in Australia. Note: the selection of the four most significant variables is taken from Figure 4 and the explanation of each school level covariate is given in Table 2.

The proportion of disadvantaged students is one of the four most important variables in all the countries except for Japan. Schools with higher proportions of disadvantaged students are those with lower estimated value-added. On average, schools with a high proportion of disadvantaged students suffer a negative impact on performances. In particular, in almost all countries, the impact of this variable on schools' value-added is negative in its range from $0 \%$ to $30 / 40 \%$.

\footnotetext{
${ }^{5}$ We only report here the figure for Australia, while the figures for other countries are reported in Appendix in Figure 9.
} 
By way of contrast, in the USA, schools in which the proportion of disadvantaged students lies between 0 and 20 tend not to differ in terms of outcomes ceteris paribus, while there is a monotonic negative association between the covariate and the response in the covariate range between 20 and 100. Thus, there are countries in which the substantial difference is between schools composed by only advantaged students and schools with a minimum proportion of disadvantaged ones, while there are countries, such as the USA, in which the the proportion of disadvantaged students is influential only if it is quite high (more than $20 \%$ ).

Another important determinant of outcomes in all countries, with the exception of Australia, is school size. In general, bigger schools are associated with higher school value-added. The impact of this variable is highly nonlinear and this can be an explanation about why some previous literature fails to find any statistical (linear) correlation between performances and size. In all countries, except for Australia and USA, the school value-added rapidly increases when the school size ranges between about 500 and 1,000 students. Schools smaller than 500 students perform in a quite similar way to schools larger than about 1,000 students. The USA provides an interesting exception: very small schools (with fewer than 500 students) are associated with very high school value-added, while there is a negative peak corresponding to schools attended by about 500 students, that is the value associated with the lowest school value-added. Again, from 500 on, larger schools are estimated to have higher value-added.

The proportion of students with special needs is important as a determinant of outcomes in all countries, except Canada and Japan. Schools with a higher proportion of students with special needs are associated to lower school valueadded. Again, there is a gap in the response value when the covariate ranges between $0 \%$ and $20 \%$. The number of schools with more than $20 \%$ of students with special needs is small, but still we have observations in this range that do not differ in their impact on the response.

Another recurrent important variable is the one measuring the students truancy. Students truancy is an indicator about how much students take seriously their presence at school and therefore, their education. In Australia, Canada, Japan and USA it is one of the four most important variables. Schools with higher proportion of students that tend to skip school days are associated to lower school value-added, in a quite intuitive way, with strong effects after a threshold when the number of days skipped is $>2.5$.

The percentage of funds given to the school from the government is a key determinant of schools' effectiveness in both Australia and Japan. In Australia, the trend is very well defined: when the percentage of funds given by the government increases, the school value-added decreases. From the literature (see [20] and [2]), we know that in Australia, private schools, which receive less funds from the government respect to public schools, are more likely to perform better than public ones and therefore these two aspects are probably strongly connected. Even if a dummy variable for public/private schools is considered, the percentage of funds given by the government still reflects some of the public/private heterogeneities and it is actually able to catch more variability in 
the response than the dummy variable. Also in Japan the partial effect of the percentage of funds given by the government on the school value-added is related to the difference between private and public schools. In Japan, contrary to Australia, PISA2015 data indicate that private schools have, on average, lower performance when compared with public schools. Moreover, private schools usually receive about $40 / 50 \%$ of their funds from the government. The trend of the impact of the covariate on the response is less clear than the one in Australia.

Lastly, in Canada and in Italy the percentage of parents speaking with teachers or participating in school governance are important. An increase in cofactor values is positively associated with the school value-added: schools in which parents are actively interested in their children's education experience more favourable outcomes than do others. Likewise, in Spain the percentage of parents participating in school governance, when in the range from 0 to $50 \%$, has a positive effect on outcomes.

The last variable that appears in the four most important variables of France, Germany, Japan and UK is the number of computers per student ("ratio comp / stud"). This covariate has a counterintuitive association with school valueadded. In Japan and UK (see Japan and UK panels in Figure 9 in Appendix), an increase of number of computers per student is associated with a decrease in school value-added. In Germany (see Germany panel in Figure 9 in Appendix), there is a peak around 0.4 and a trough around 0.6. Lastly, in France (see France panel in Figure 9 in Appendix), the highest value-added corresponds to zero computers, but there is a peak around 1, maybe suggesting that one computer per person is the right balance. A possible interpretation of these trends is that too many computers (more than one per person) may be sign of inefficient management of school funds. Alternatively it might be the case that national policies have concentrated the IT facilities in less advantaged schools with lower test scores - in this case, the statistical relationship would be biased.

\subsubsection{Describing the impact of joint variables on schools' value- added}

Up to this point, we have investigated the partial effect of predictors one by one, on a ceteris paribus basis. But one of the main strengths of the regression tree approach is that it allows consideration of circumstances in which more than one cofactor changes simultaneously, so affecting simultaneously the dependent variable (in our case, school value-added). We now turn, therefore, to focus on the visualisation of the joint effect of two predictors on the response, and in so doing investigate the interaction effect of the most significant variables within each country (Figure 6) ${ }^{6}$. Again, the choice of the variables to be included in the graphical illustration is based on the variables that, in the different countries, turned out to be most important in affecting the estimated schools' value-added.

\footnotetext{
${ }^{6}$ We only report here the figure for Australia, while the figures for other countries are reported in Appendix in Figure 10.
} 

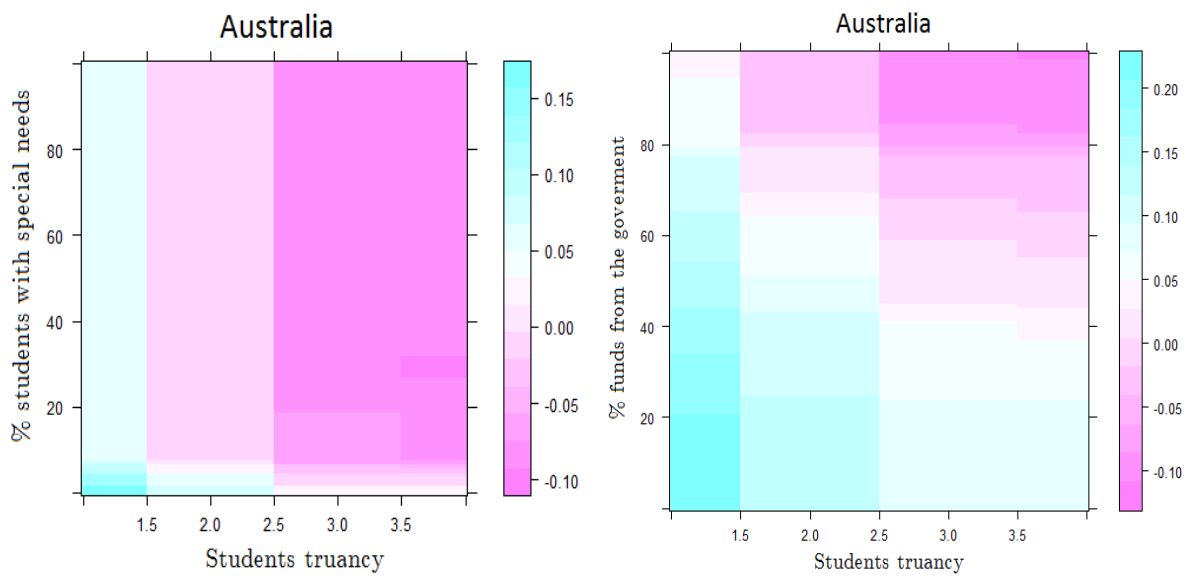

Figure 6: Joint partial plot of the most important school level variables in association with school value-added, in Australia. Notes: 1. Colors represent the scale of the values of the response (school value-added). 2. The selection of variables is based on the group of the variables that turn out to be significant in previous steps.

In several countries, the impact on outcomes of the joint association between the proportion of disadvantaged students and school size is of interest. From Australia and USA panels, we know that in most countries larger schools perform better than smaller ones and schools with a high proportion of disadvantaged students perform less successfully than others. The extent to which differences in school size affect outcomes depends critically on how high is the proportion of disadvantaged students, however. In Italy and Spain, the proportion of disadvantaged students seems to have a clear negative impact even in the big schools, while small schools with a low proportion of disadvantaged students are not associated with negative effect on value-added. In UK and USA, the interaction is much weaker in the sense that the high proportion of disadvantaged students has a negative impact, almost independently from the school size. The difference between these two countries is that while in UK the threshold value of proportion of disadvantaged students to have a negative impact on the response is about $20 / 30 \%$, in the USA is much higher, around $70 / 80 \%$.

Interaction between two variables about the students' socioeconomic composition - namely the proportion of socioeconomically disadvantaged students and proportion of students with special needs - is also interesting and instructive. In France, schools in which both percentages are low perform better than the average while schools where both percentages are high perform worse. However, schools with a high proportion of disadvantaged students nevertheless manage average performance if they have a very small proportion of students with special needs (and vice versa). In Germany and Italy, schools with a low proportion 
of disadvantaged students perform better than the average and the increasing proportion of students with special needs does not affect this performance. On the contrary, schools with a high proportion of disadvantaged students perform worse than the average and the increasing proportion of students with special needs worsens the results even more. In UK, the increase in both proportions contributes to lower school value-added in an almost symmetric way.

Truancy is another variable whose interaction with school size and school body composition is worthy of investigation. "Truancy" is defined by OECD as the propensity for students to skip classes without justification. In Japan, truancy is associated with very low school value-added only when considering small schools, while, even if it has again a negative impact, we still have positive school value-added in big schools with high students truancy. In USA, schools with low levels of truancy perform better than the average while schools with high truancy rates perform worse than the average, but there is an important interaction with school size - truancy has a more negative association to test scores in smaller rather than in larger schools. In Australia and in Canada, the interaction between students truancy and proportion of disadvantaged students is similar: schools with both high (low) truancy and high (low) proportion of disadvantaged students are associated with negative (positive) school value-added. But, schools with high truancy rates and a low proportion of disadvantaged students (and vice versa), are still able to achieve average performance.

In Australia and Japan, truancy and percentage of funds given by the government are very important variables but they interact in an heterogeneous way to affect schools' performance. In Australia, schools with both high (low) students truancy and high (low) percentage of funds given by the government are associated with negative (positive) effects on school value-added, but, in all the other cases, this relationship doen not hold. Instead in Japan, schools with low (high) students truancy perform worse (better) than the average, almost independently from the percentage of funds given by the government.

The last interaction that deserves attention is the one between school size and percentage of parents participating in school governance in Spain: the size of the school is associated with positive school value-added, but only if parents actively participate at the school government and are interested in their children's education.

The visualization of joint partial plots to characterise the determinants of schools' value-added proves to be a powerful tool for analysts and decision makers. Indeed, these figures provide an immediate sense of which are the variables with more or less influence on schools' value-added, while simultaneously providing information covering the whole distribution of the impacting variables, without forcing to concentrate on average correlations. 


\section{Discussion, concluding remarks and policy im- plications}

The availability of large scale datasets allowing comparative analysis of educational performance has been a major boost to researchers interested in the educational production function. In this paper, we have applied new methods of analysis, drawn from the machine learning literature, to examine the determinants of students' test scores and schools' value-added. The results confirm many of the relationships we knew already from statistical analysis, but provide a new and enriched understanding of how both nonlinearities amongst and interactions between cofactors determine educational performance. These insights come from a recognition that the education process is complex, unknown in its specific mechanisms and heterogeneous across countries. The tree-based methods that we use represent an inductive and non deductive way to explain the associations among variables, having two main advantages respect to the classical statistical methods: they do not force any functional relationships between the response (students' results) and the covariates (students' characteristics) and they allow for interactions among the variables.

The first stage of our analysis shows that student-level variables are able to explain part of the variability in their achievements: socio-economic index, anxiety, motivation, gender, and parental education are some of the most influential variables. Their association to test scores and their ability in explaining variability in students' achievements are differ substantially across countries. The percentage of variability in students' achievements explained at school level (schools' value-added in our terminology here) also varies across countries. Those countries in which the estimated variance of schools' value-added is high are characterised by heterogeneity at school level. On the contrary, countries where the variance of schools' value-added is limited in magnitude offer a more homogeneous experience across schools. There are clear policy implications in noting, for example, that the ratio of students to teachers has high relative influence in Canada, Japan and Spain, but not elsewhere. In many countries, the actions that can most effectively improve educational outcomes are not educational policies per se, but rather social policies.

After estimating the school value-added in the first stage, we correlate it to school level characteristics in the second stage. Again, we find different school level variables associated to school value-added across countries. The main focus in this stage is the effect of interactions between cofactors, which is modelled by means of joint partial plots. As we have seen, the impact on performance of changes in one variable often depends crucially on the value of other explanatory variables.

Tree-based methods complement linear regression models of educational performance by augmenting them with a richer interrogation of the data. The impact of student and school level variables are often not simply linearly asso-

ciated with students' achievements; we have uncovered evidence in the data of considerably more complex (and intuitively plausible) patterns. The strength 
of the machine learning method, in this perspective, is that they literally "learn from the data", finding the dominant patterns without any assumption. Armed with the refined understanding of how different policies can impact differently on schools in various circumstances, policy-makers can better implement change aimed at improved performance.

Several policy implications can be drawn from our analysis. The results show the relationship between test scores and both school and individual factors to be quite complex, and this presents a challenge to naïve interpretations of school performance tables. A particularly salient aspect of this complexity relates to differences across countries in the impact on educational performance of variables that are not usually thought to pertain to educational policy. Notably in several countries in this study (but not in others), the first branch of the regression tree is defined by ESCS - indicating that (in these countries, but not elsewhere) issues in the sphere of education might most effectively be addressed using social rather than educational policies. The machine learning tools used thus highlight in sharp relief some issues with high policy relevance.

The results obtained in the present paper should be viewed alongside other research drawn from the literature on educational production functions. In common with much contemporary applied economic research, these studies place emphasis on causality. Further research is needed to introduce sophisticated analysis of causality in the machine learning context, specifically as it applies in the sphere of education.

\section{Acknowledgements}

The authors are grateful to Professor Anna Maria Paganoni for the statistical support during the work. 


\section{References}

[1] Tommaso Agasisti, Francesca Ieva, and Anna Maria Paganoni. Heterogeneity, school-effects and the north/south achievement gap in italian secondary education: evidence from a three-level mixed model. Statistical Methods $\mathbb{E} \mathfrak{G}$ Applications, pages 1-24, 2016.

[2] DS Anderson. Public schools in decline: Implications of the privatization of schools in australia. Restructuring schools, pages 184-199, 1993.

[3] Joshua D Angrist and Victor Lavy. Using maimonides' rule to estimate the effect of class size on scholastic achievement. The Quarterly Journal of Economics, 114(2):533-575, 1999.

[4] Leo Breiman. Random forests. Machine learning, 45(1):5-32, 2001.

[5] Leo Breiman, Jerome Friedman, Charles J Stone, and Richard A Olshen. Classification and regression trees. CRC press, 1984.

[6] Anthony S Bryk and Stephan W Raudenbush. Toward a more appropriate conceptualization of research on school effects: A three-level hierarchical linear model. American journal of Education, 97(1):65-108, 1988.

[7] James S Coleman, Ernest Campbell, Carol Hobson, James McPartland, Alexander Mood, Frederick Weinfeld, and Robert York. The coleman report. Equality of Educational Opportunity, 1966.

[8] Paulo Cortez and Alice Maria Gonçalves Silva. Using data mining to predict secondary school student performance. EUROSIS, 2008.

[9] Jane Elith, John R Leathwick, and Trevor Hastie. A working guide to boosted regression trees. Journal of Animal Ecology, 77(4):802-813, 2008.

[10] Trevor Fitzpatrick and Christophe Mues. An empirical comparison of classification algorithms for mortgage default prediction: evidence from a distressed mortgage market. European Journal of Operational Research, 249(2):427-439, 2016.

[11] Jerome H Friedman. Greedy function approximation: a gradient boosting machine. Annals of statistics, pages 1189-1232, 2001.

[12] Florence Gabriel, Jason Signolet, and Martin Westwell. A machine learning approach to investigating the effects of mathematics dispositions on mathematical literacy. International Journal of Research $\&$ Method in Education, pages 1-22, 2017.

[13] J Paul Grayson. Academic achievement of first-generation students in a canadian university. Research in higher Education, 38(6):659-676, 1997.

[14] Eric A Hanushek. Education production functions. The New Palgrave Dictionary of Economics. Basingstoke: Palgrave Macmillan, 2008. 
[15] Eric A Hanushek, Steven G Rivkin, and Lori L Taylor. Aggregation and the estimated effects of school resources. Technical report, National bureau of economic research, 1996.

[16] Eric A Hanushek and Ludger Woessmann. The High Cost of Low Educational Performance: The Long-Run Economic Impact of Improving PISA Outcomes. ERIC, 2010.

[17] Gareth James, Daniela Witten, Trevor Hastie, and Robert Tibshirani. An introduction to statistical learning, volume 6. Springer, 2013.

[18] Wei-Yin Loh, John Eltinge, MoonJung Cho, and Yuanzhi Li. Classification and regression tree methods for incomplete data from sample surveys. arXiv preprint arXiv:1603.01631, 2016.

[19] Xin Ma. Growth in mathematics achievement: Analysis with classification and regression trees. The Journal of Educational Research, 99(2):78-86, 2005 .

[20] Simon Marginson. Education and public policy in Australia. Cambridge University Press, 1993.

[21] Chiara Masci, Francesca Ieva, Tommaso Agasisti, and A M. Paganoni. Bivariate multilevel models for the analysis of mathematics and reading pupils' achievements. Journal of Applied Statistics, pages 1-22, 2016.

[22] Chiara Masci, Francesca Ieva, Tommaso Agasisti, and Anna Maria Paganoni. Does class matter more than school? evidence from a multilevel statistical analysis on italian junior secondary school students. SocioEconomic Planning Sciences, 54:47-57, 2016.

[23] Sendhil Mullainathan, Jann Spiess, et al. Machine learning: an applied econometric approach. Journal of Economic Perspectives, 31(2):87-106, 2017.

[24] OECD. Pisa 2015 results (volume 1).

[25] Gary Orfield, John Kucsera, and Genevieve Siegel-Hawley. E pluribus... separation: Deepening double segregation for more students. UCLA: The Civil Rights Project/Proyecto Derechos Civiles. Retrieved from: http://escholarship.org/uc/item/8g58m2v9, 2012.

[26] TAYA L Owens. Thinking beyond league tables: A review of key pisa research questions. PISA, power, and policy: The emergence of global educational governance, pages 27-49, 2013.

[27] Ismael Peña-López et al. Pisa 2015 results (volume i). excellence and equity in education. 2016. 
[28] Ian Plewis. Contextual variations in ethnic group differences in educational attainments. Journal of the Royal Statistical Society: Series A (Statistics in Society), 174(2):419-437, 2011.

[29] R Core Team. R: A Language and Environment for Statistical Computing. R Foundation for Statistical Computing, Vienna, Austria, 2014.

[30] Stephen Raudenbush and Anthony S Bryk. A hierarchical model for studying school effects. Sociology of education, pages 1-17, 1986.

[31] Stephen W Raudenbush. Educational applications of hierarchical linear models: A review. Journal of Educational Statistics, 13(2):85-116, 1988.

[32] Steven G Rivkin, Eric A Hanushek, and John F Kain. Teachers, schools, and academic achievement. Econometrica, 73(2):417-458, 2005.

[33] Russell W Rumberger. Dropping out of middle school: A multilevel analysis of students and schools. American educational Research journal, 32(3):583$625,1995$.

[34] Roberto Savona. Hedge fund systemic risk signals. European Journal of Operational Research, 236(1):282-291, 2014.

[35] Robert E Schapire. The boosting approach to machine learning: An overview. In Nonlinear estimation and classification, pages 149-171. Springer, 2003.

[36] Rebecca J Sela and Jeffrey S Simonoff. Re-em trees: a data mining approach for longitudinal and clustered data. Machine learning, 86(2):169$207,2012$.

[37] Tom AB Snijders. Multilevel analysis. Springer, 2011.

[38] Kaye Stacey. The international assessment of mathematical literacy: Pisa 2012 framework and items. In Selected regular lectures from the 12th International Congress on Mathematical Education, pages 771-790. Springer, 2015 .

[39] Emily H Thomas and Nora Galambos. What satisfies students? mining student-opinion data with regression and decision tree analysis. Research in Higher Education, 45(3):251-269, 2004.

[40] Hal R Varian. Big data: New tricks for econometrics. The Journal of Economic Perspectives, 28(2):3-27, 2014.

[41] J Douglas Willms and Stephen W Raudenbush. A longitudinal hierarchical linear model for estimating school effects and their stability. Journal of educational measurement, 26(3):209-232, 1989. 
[42] Alexander W Wiseman, Heinz-Dieter Meyer, and Aaron Benavot. Policy responses to pisa in comparative perspective. PISA, power, and policy: The emergence of global educational governance, pages 303-322, 2013.

[43] Elizabeth Word et al. Student/teacher achievement ratio (star) tennessee's k-3 class size study. final summary report 1985-1990. 1990. 


\section{Appendix}
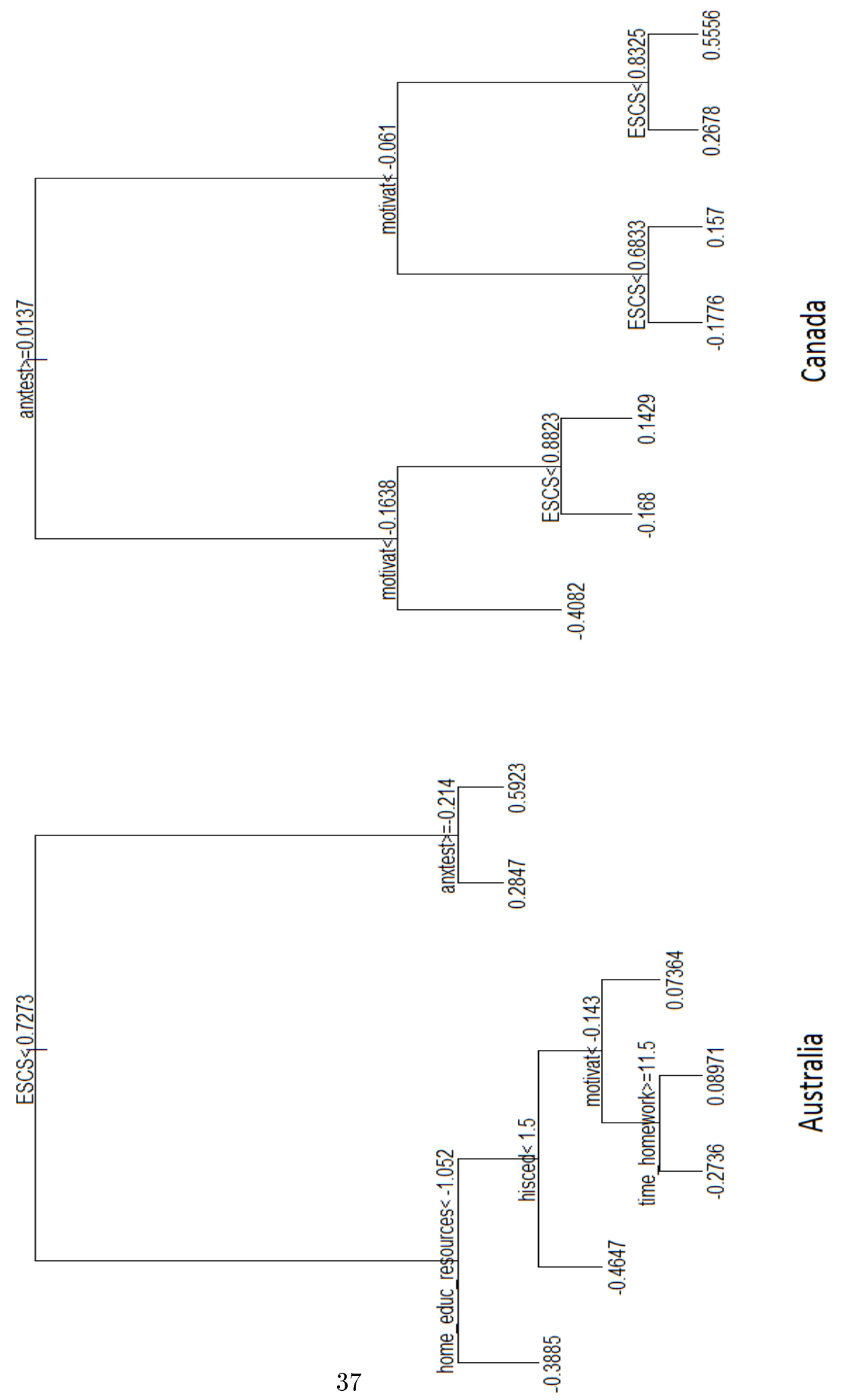

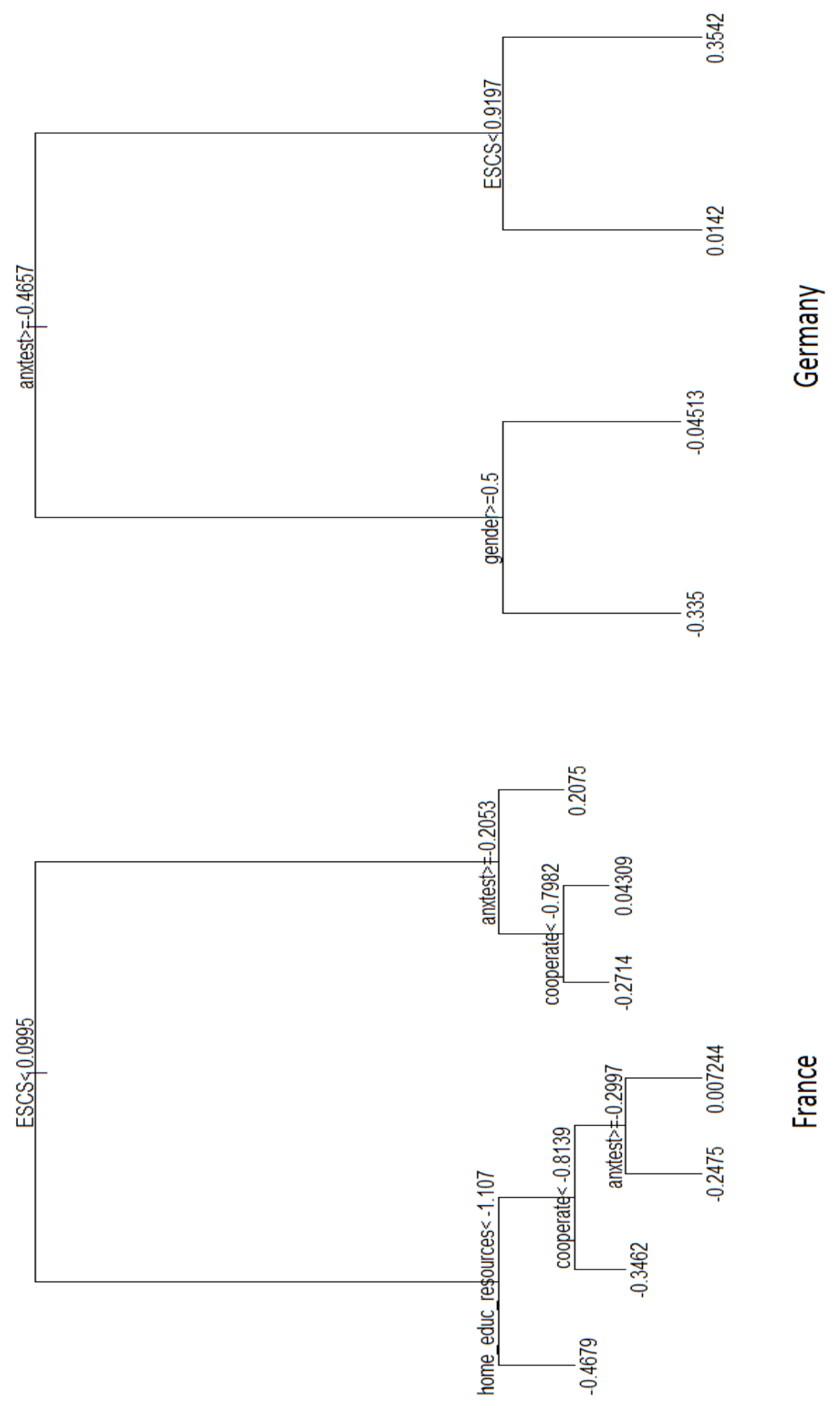

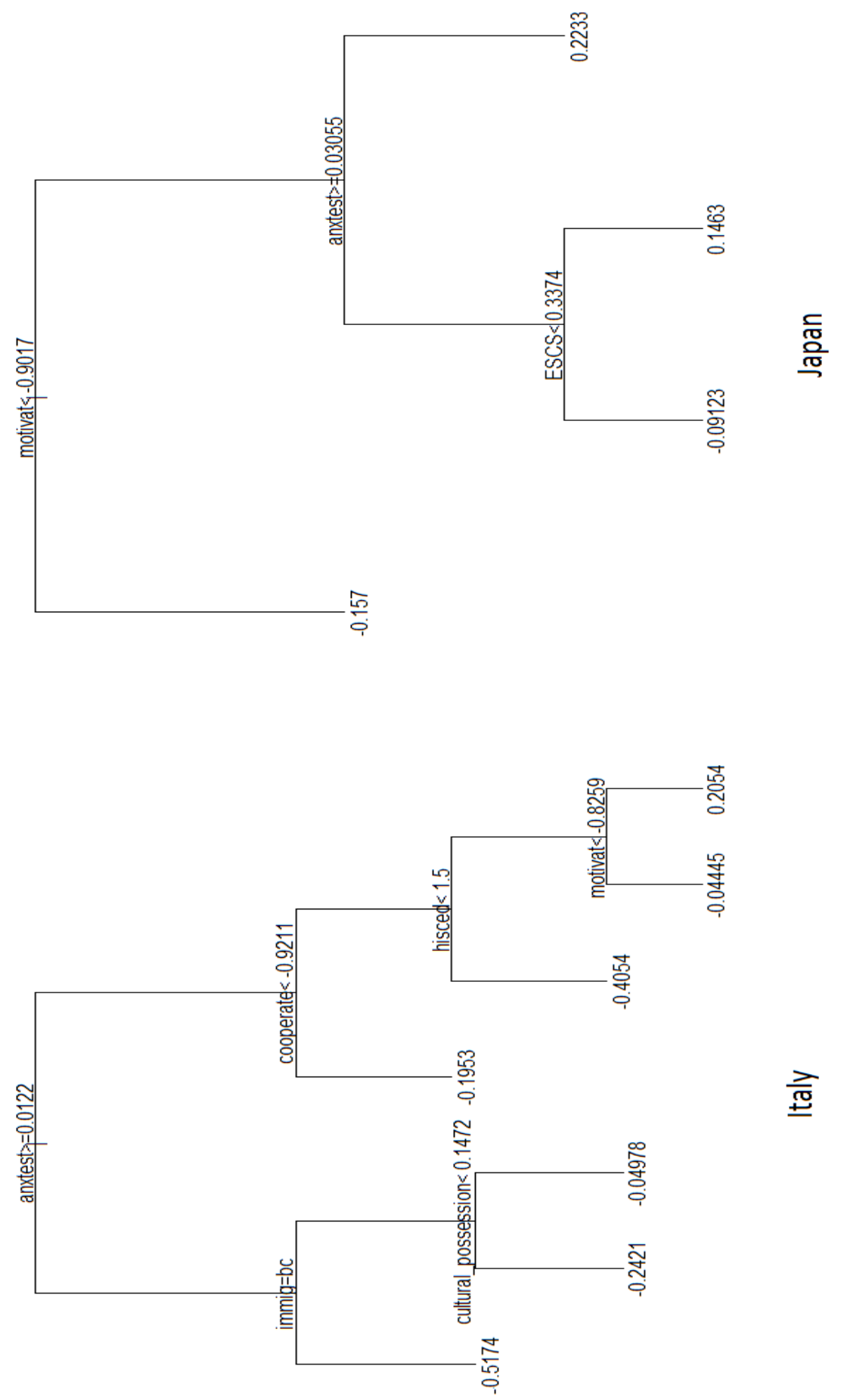

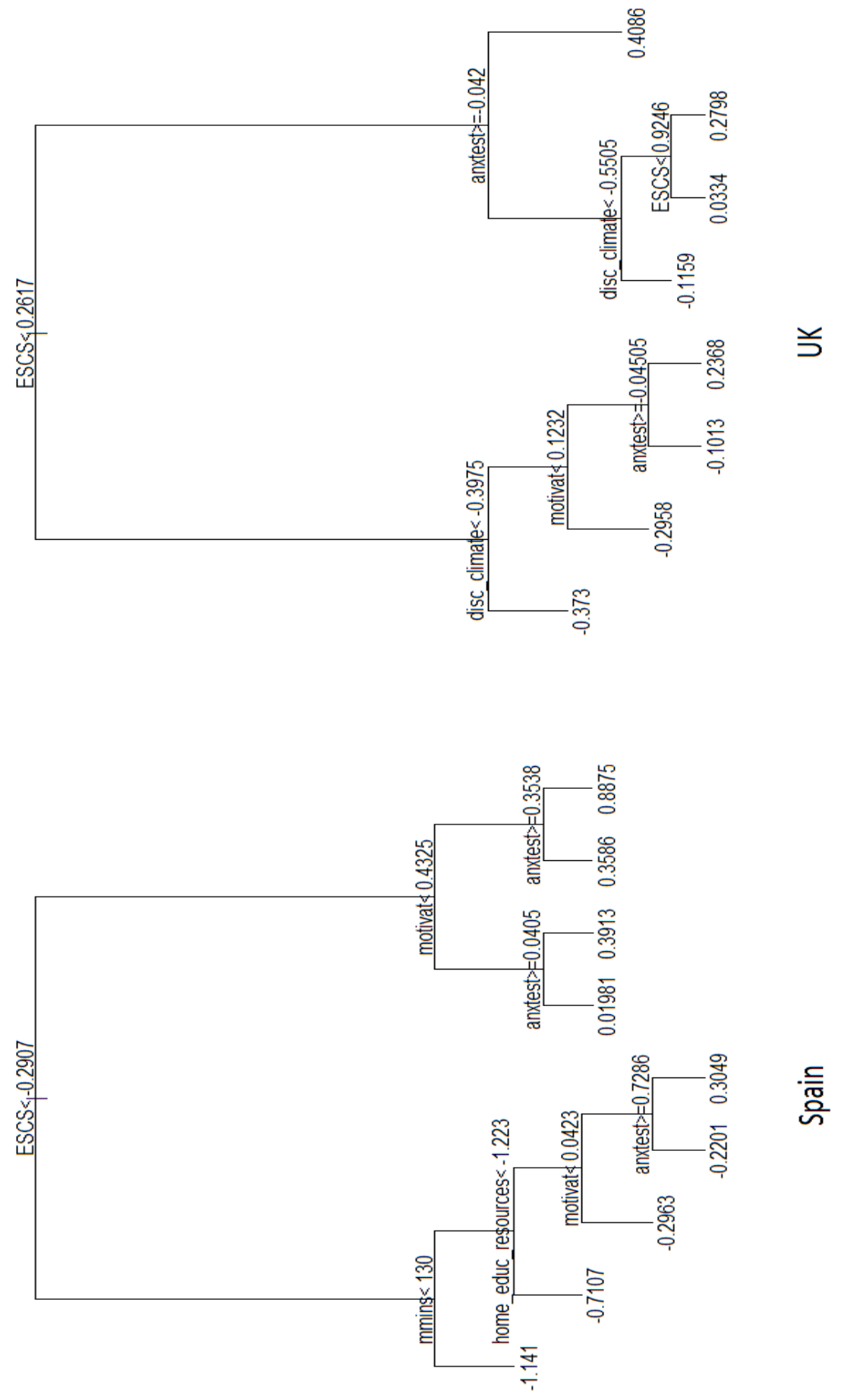


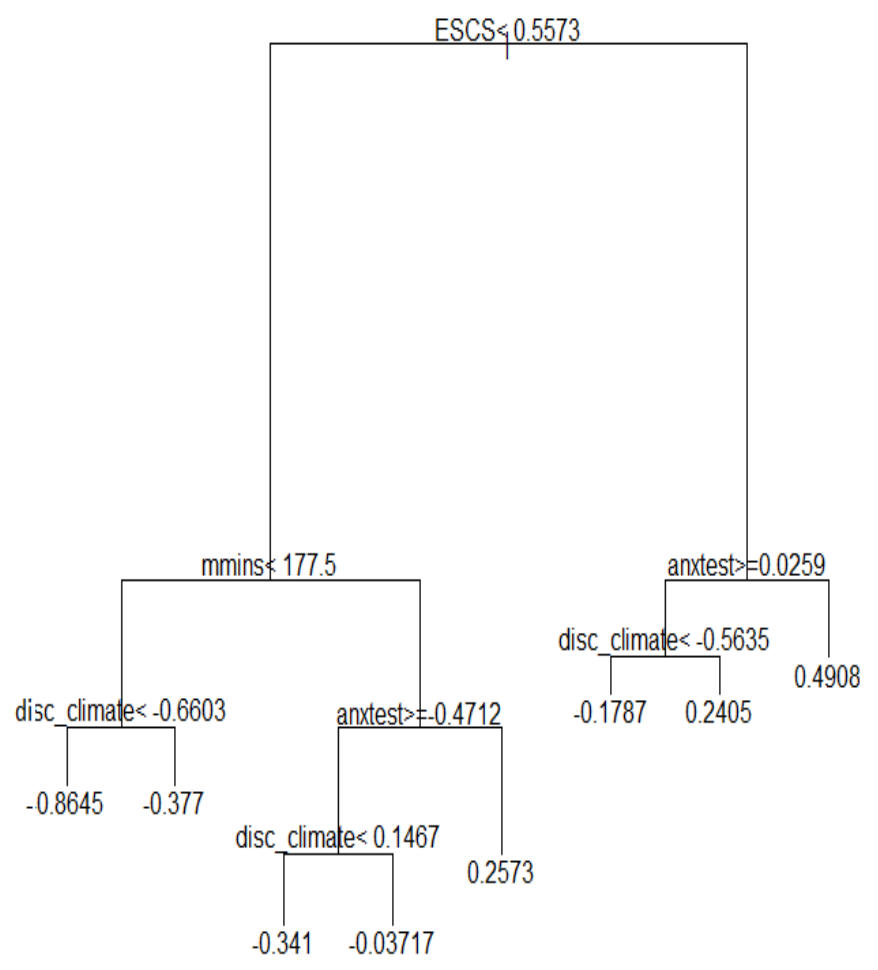

USA

Figure 7: Fixed effect trees of first stage analysis (RE-EM tree in model 5) in the 9 countries. 

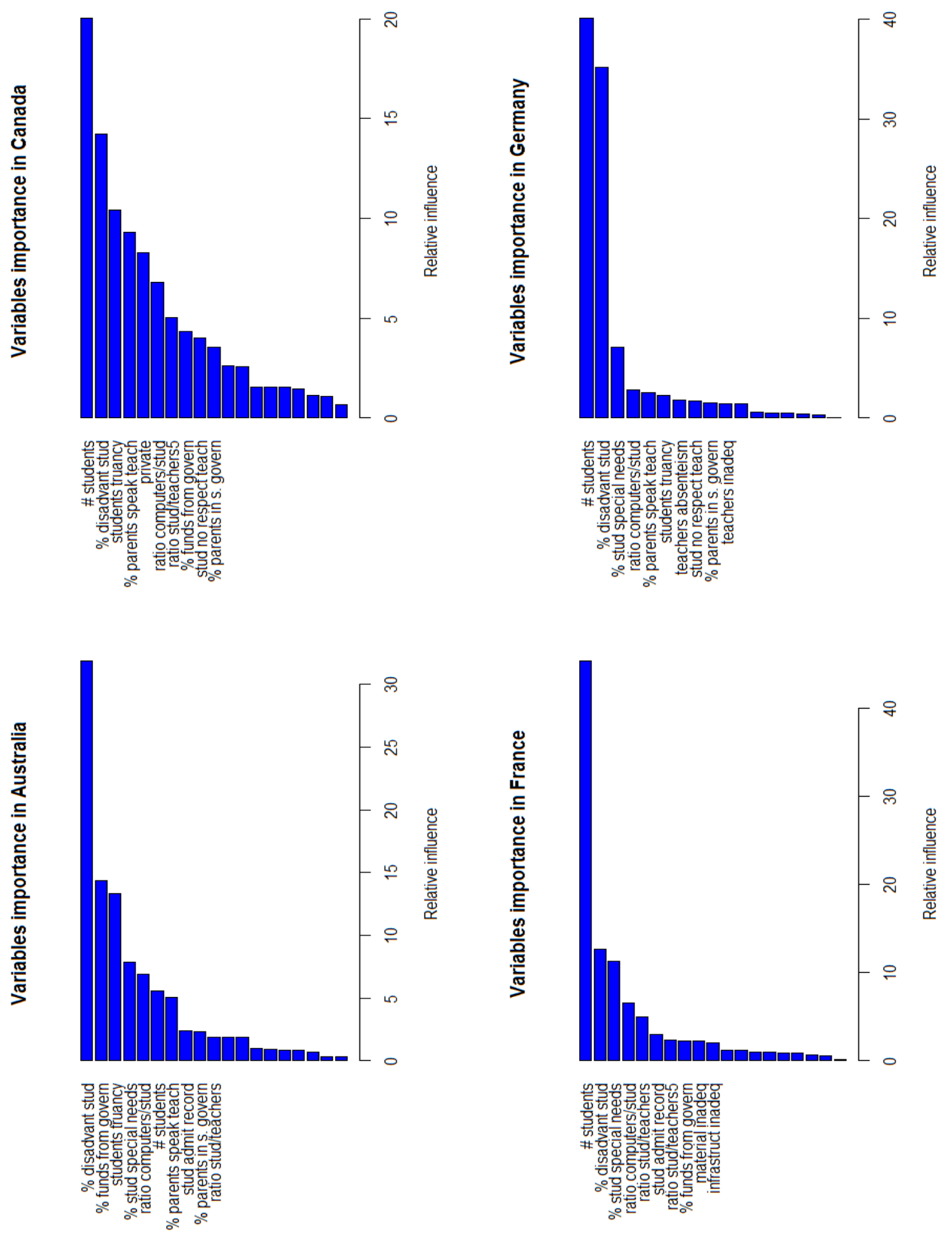

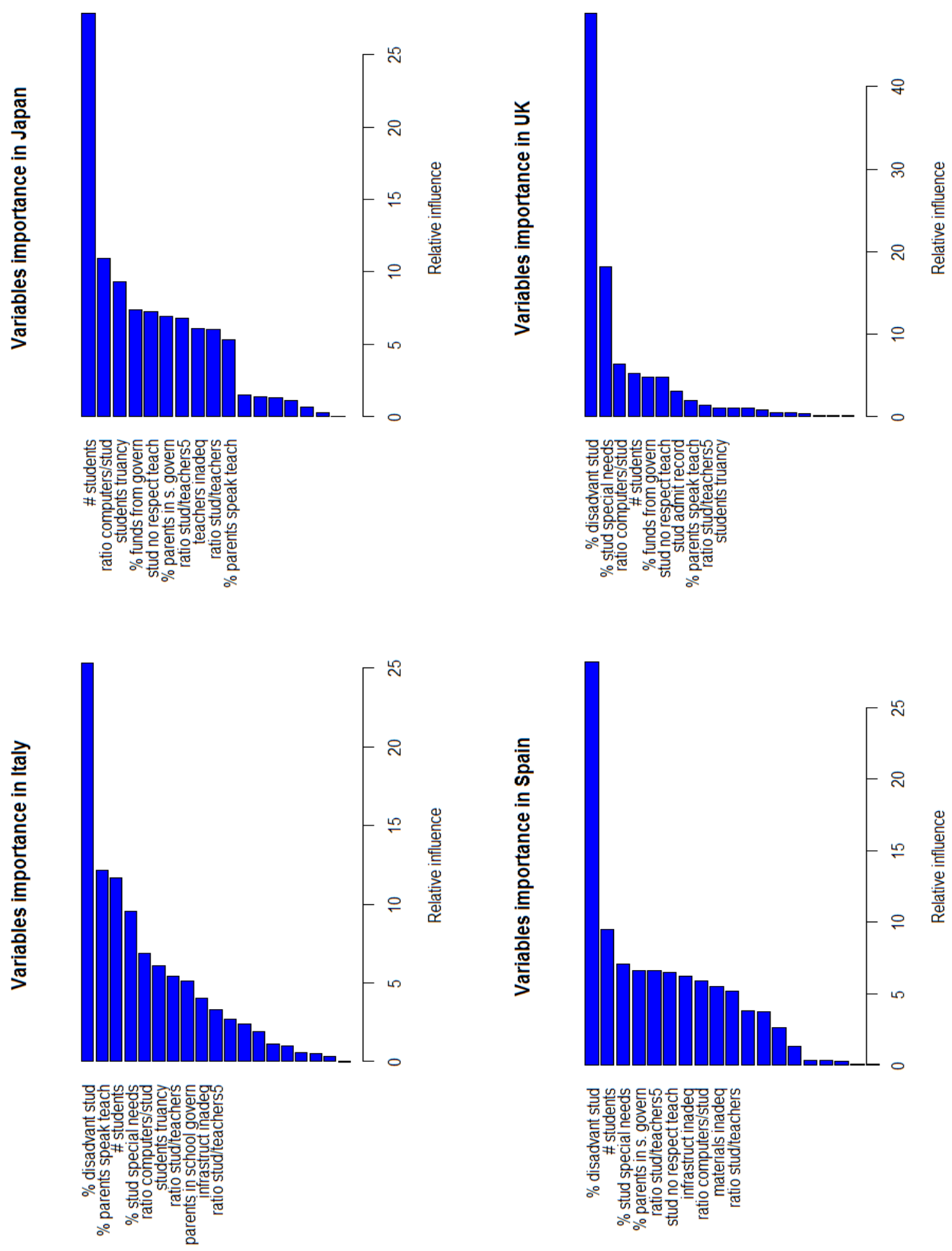


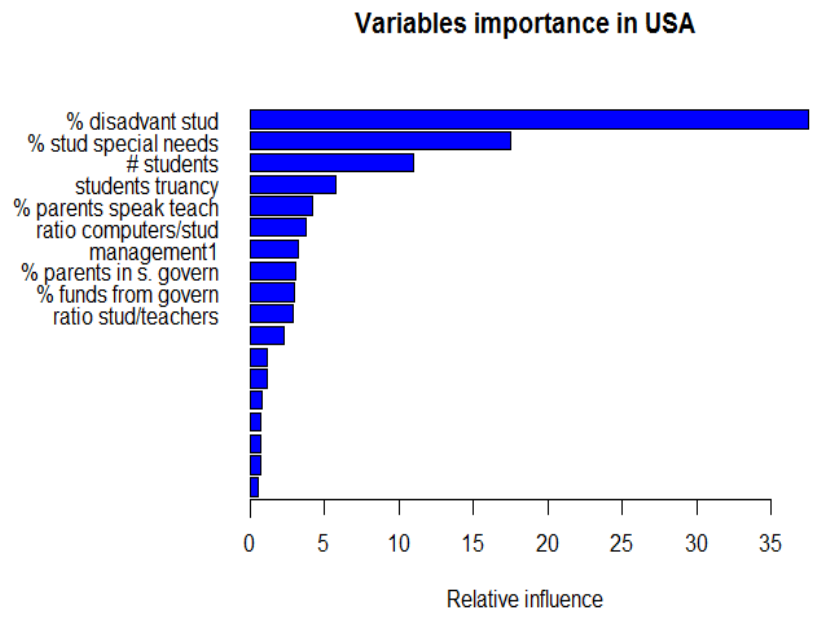

Figure 8: School level variables importance ranking in the second stage of the analysis. For each country, Boosting creates a ranking of the relative influences of the covariates on the outcome variable (school value-added). To lighten the reading, we report here only the first ten most important variables within each country (where the most important variable is the one able to catch the bigger part of variability in the outcome). 


\section{Australia}
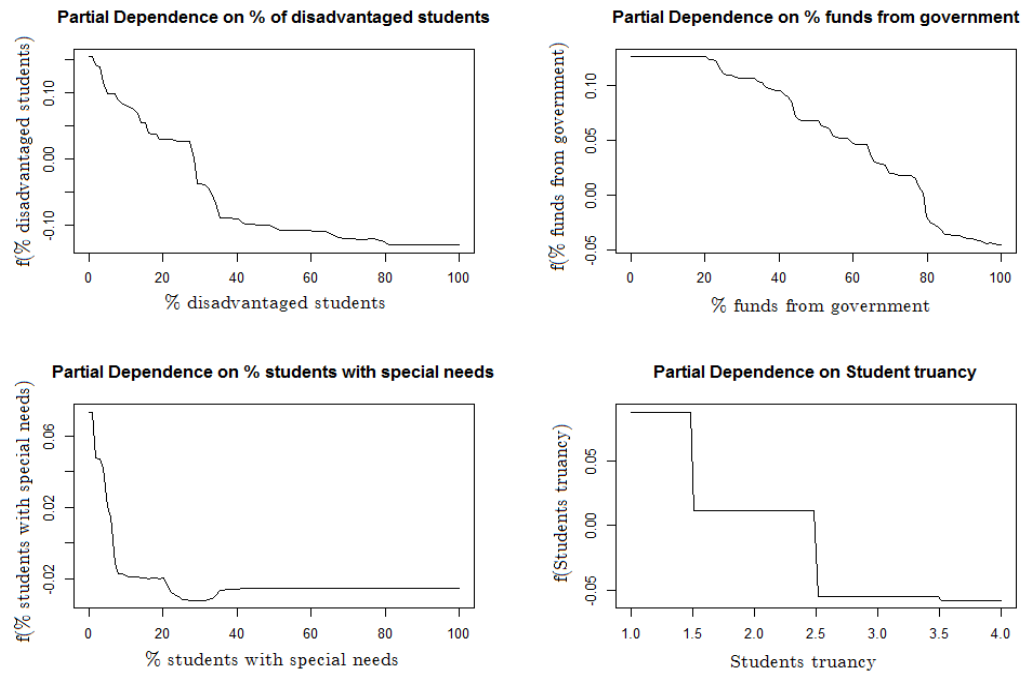

\section{Canada}
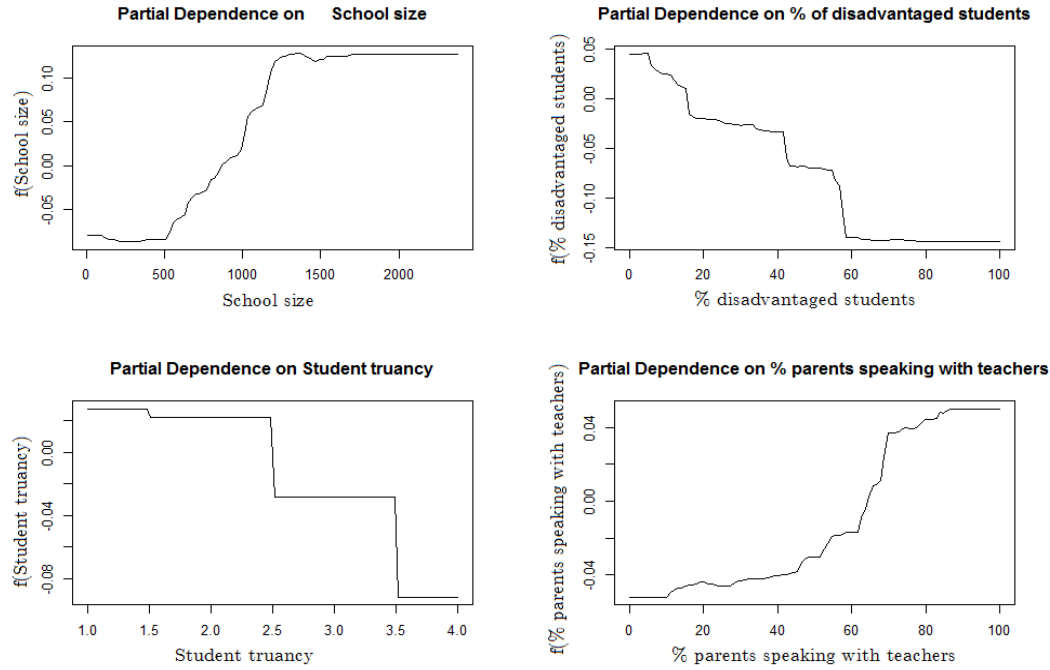


\section{France}
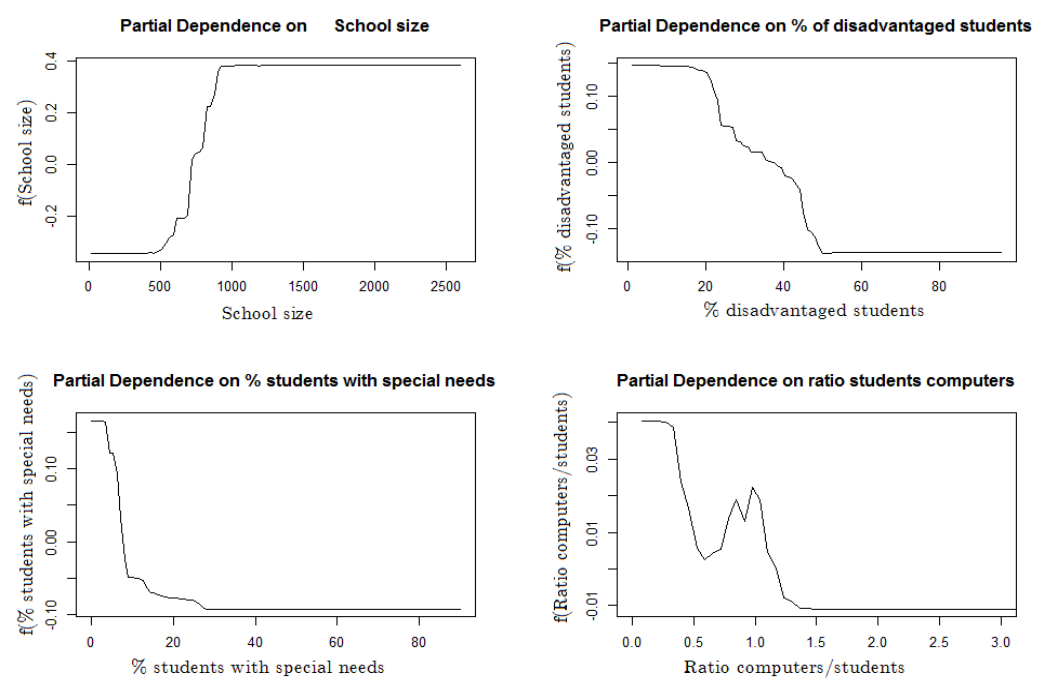

\section{Germany}
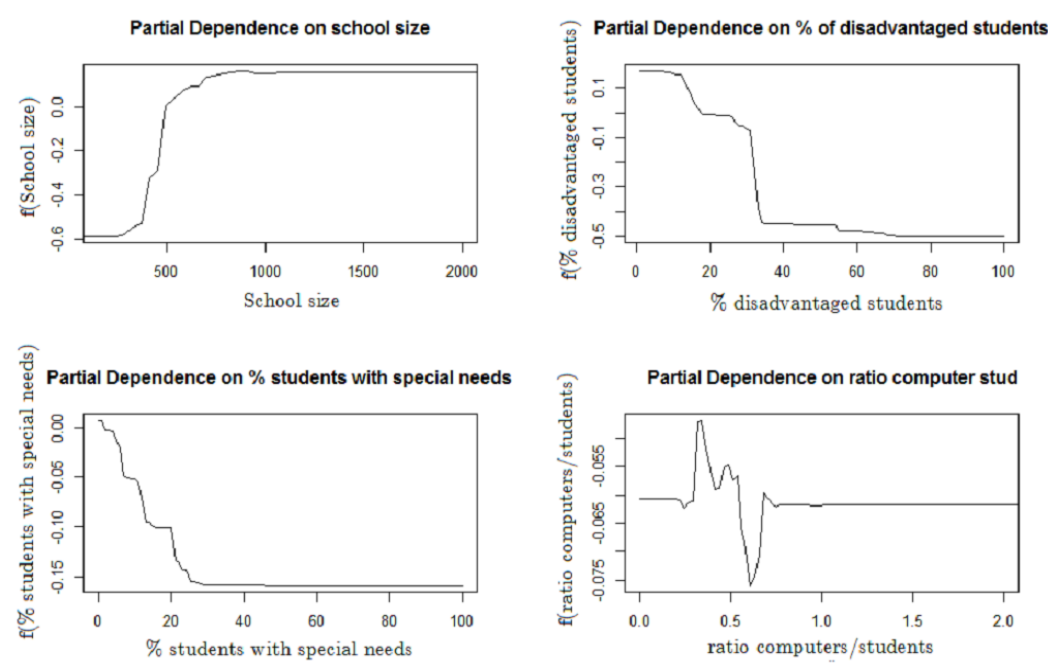
Italy
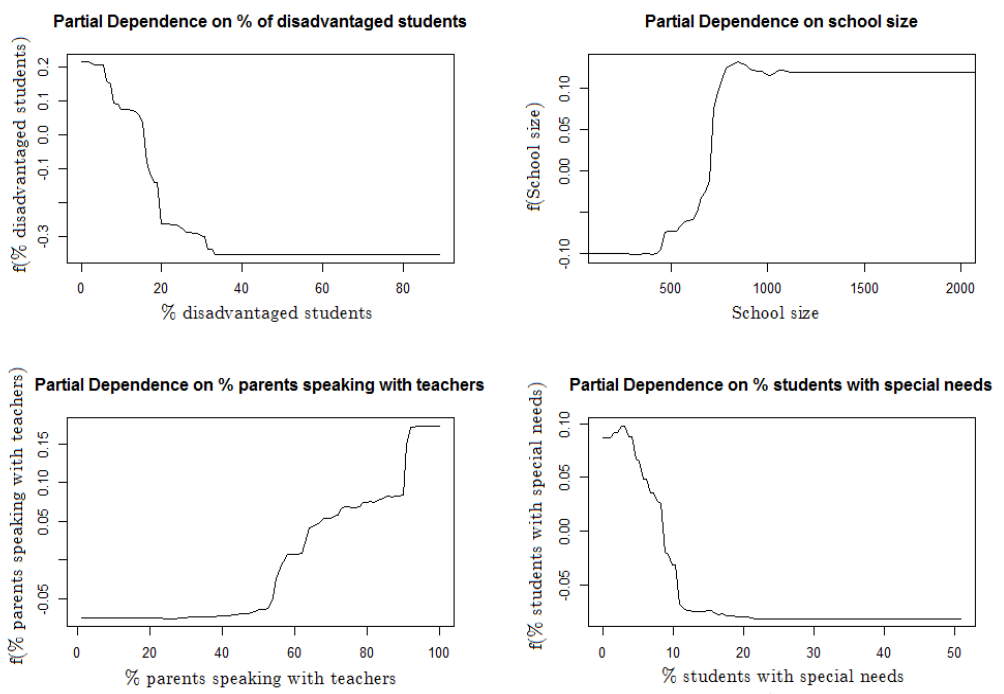

Japan
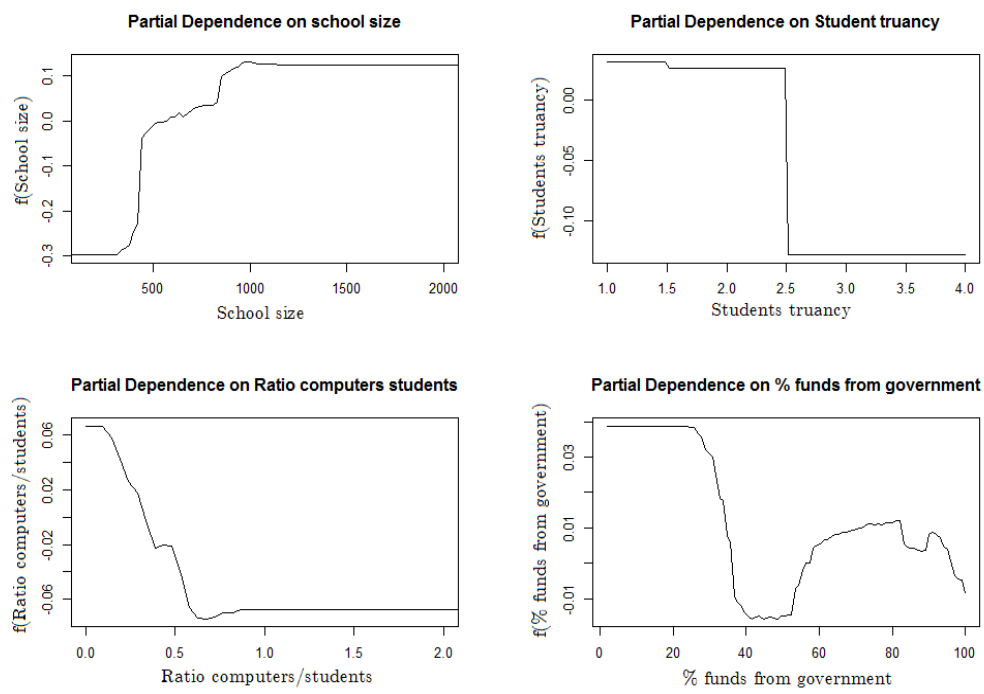
Spain
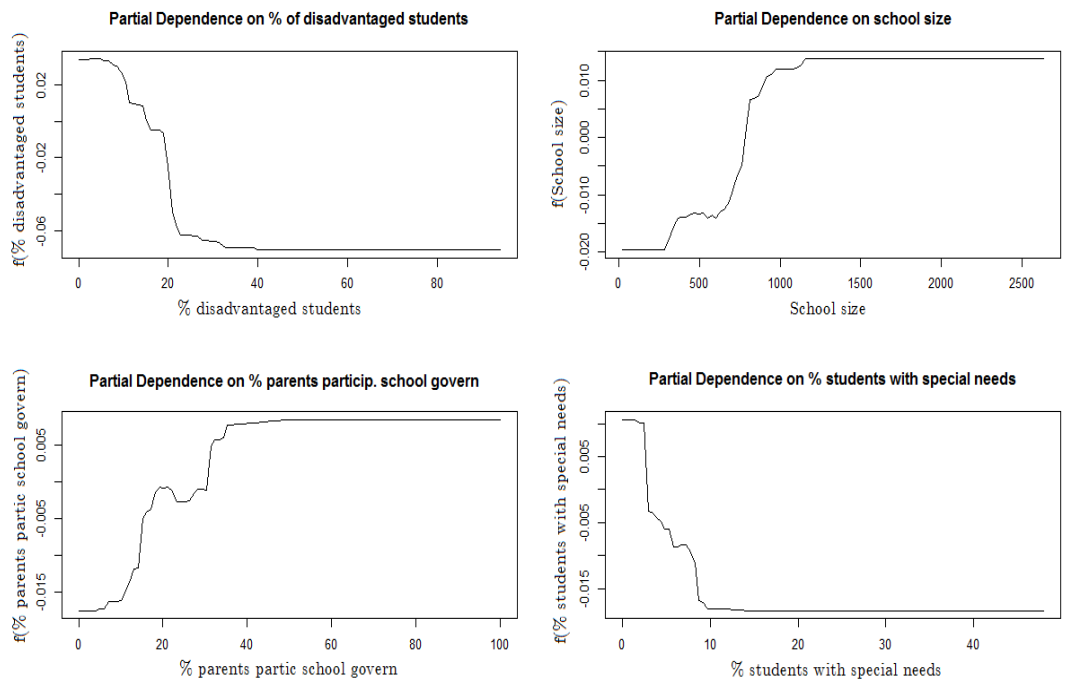

UK
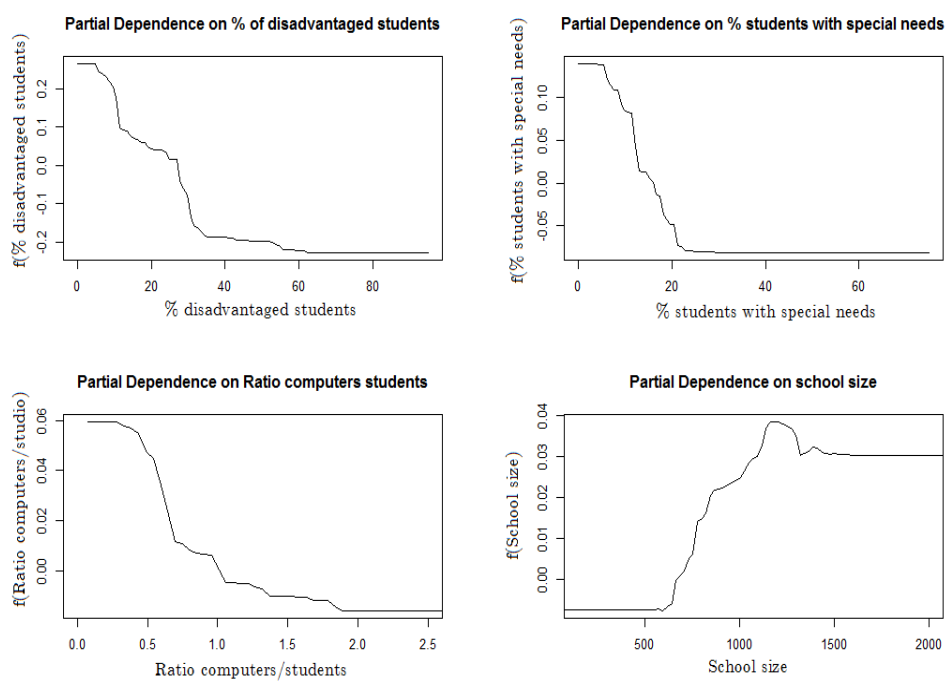

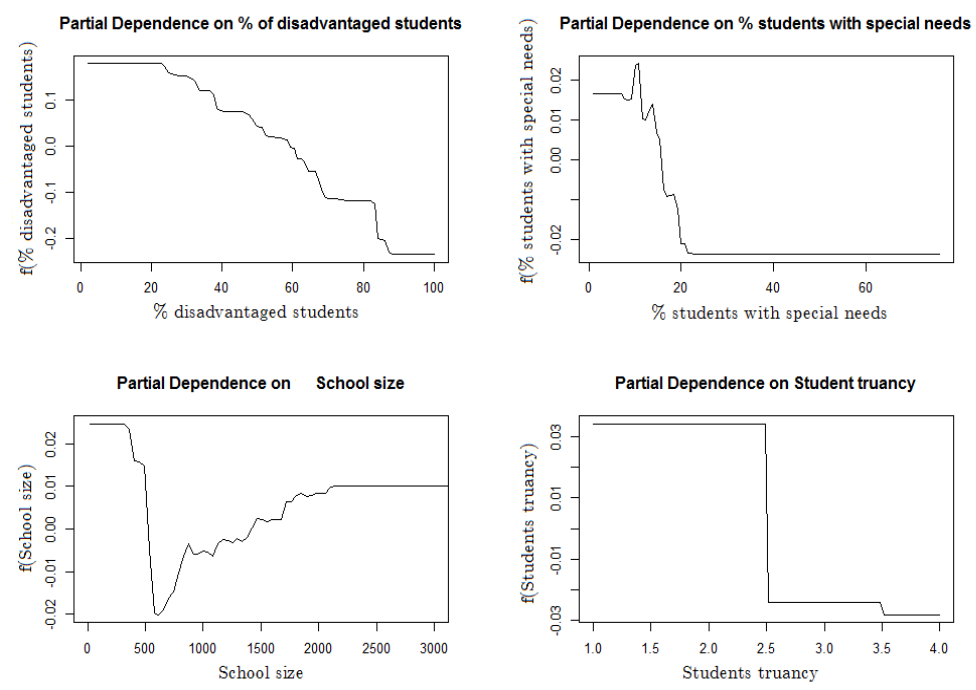

Figure 9: Partial plot of the four most important school level variables in the association with school value-added, in each country. Note: the selection of the four most significant variables within each country is taken from Figure 8 and the explanation of each school level covariate is given in Table 2. 

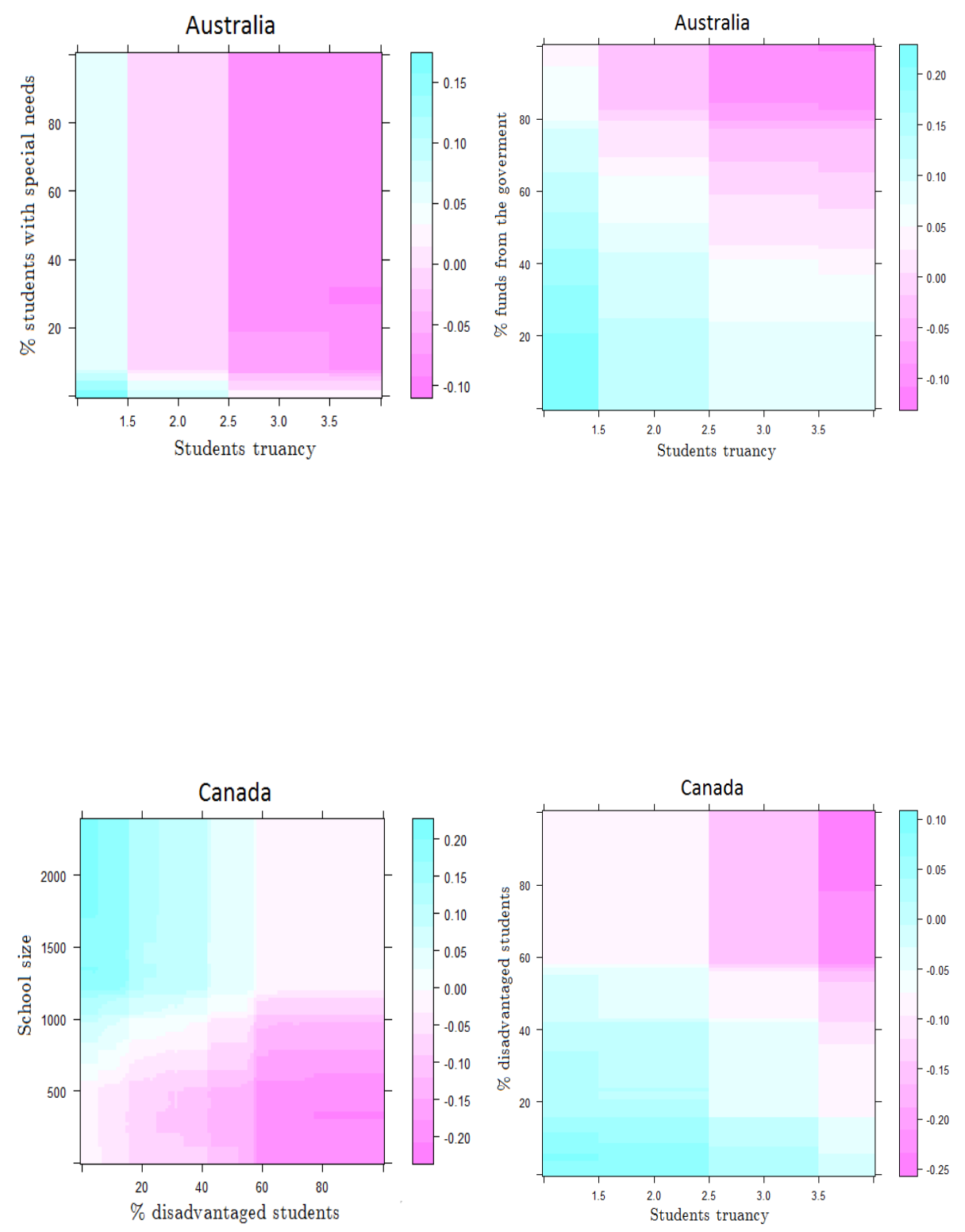

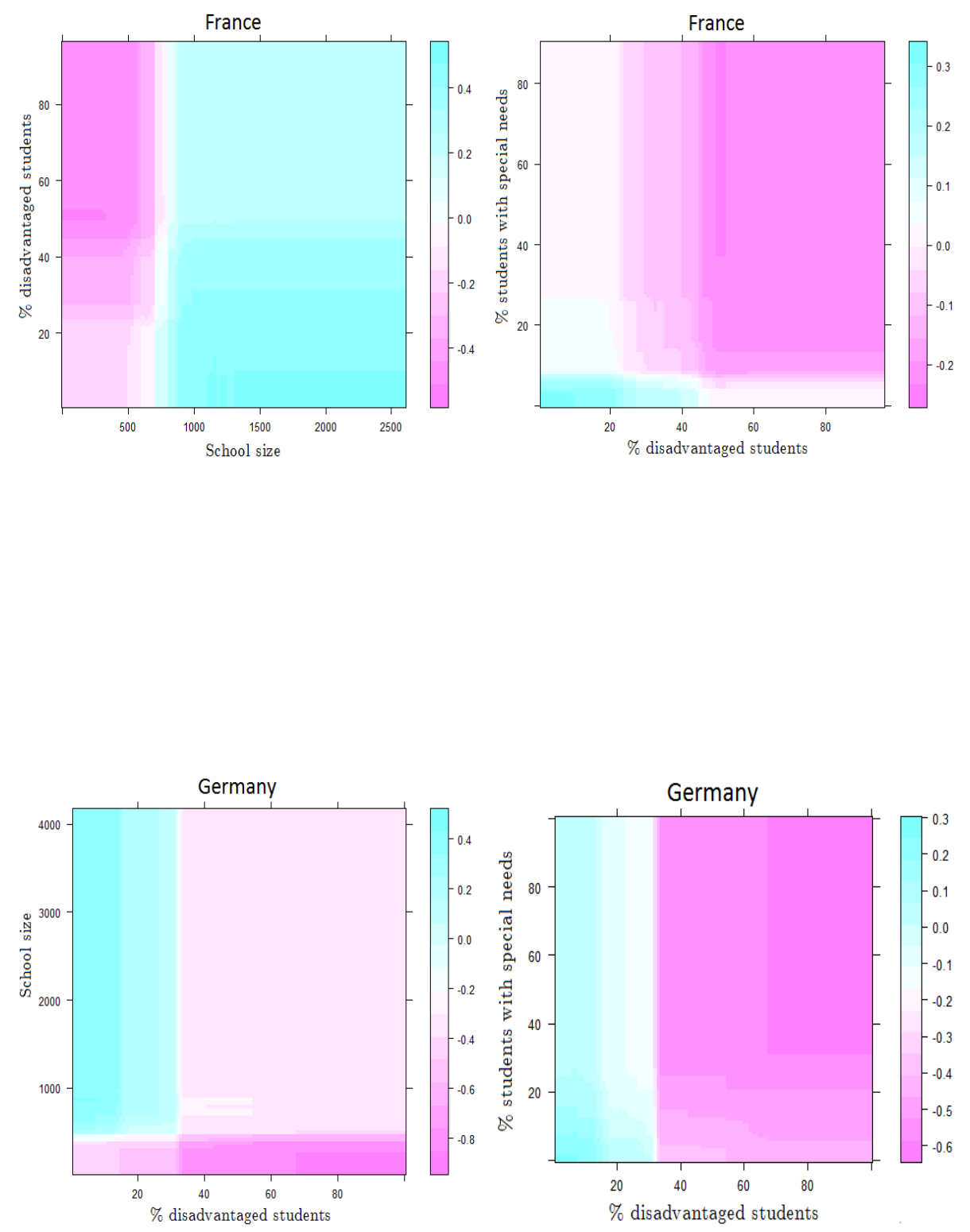

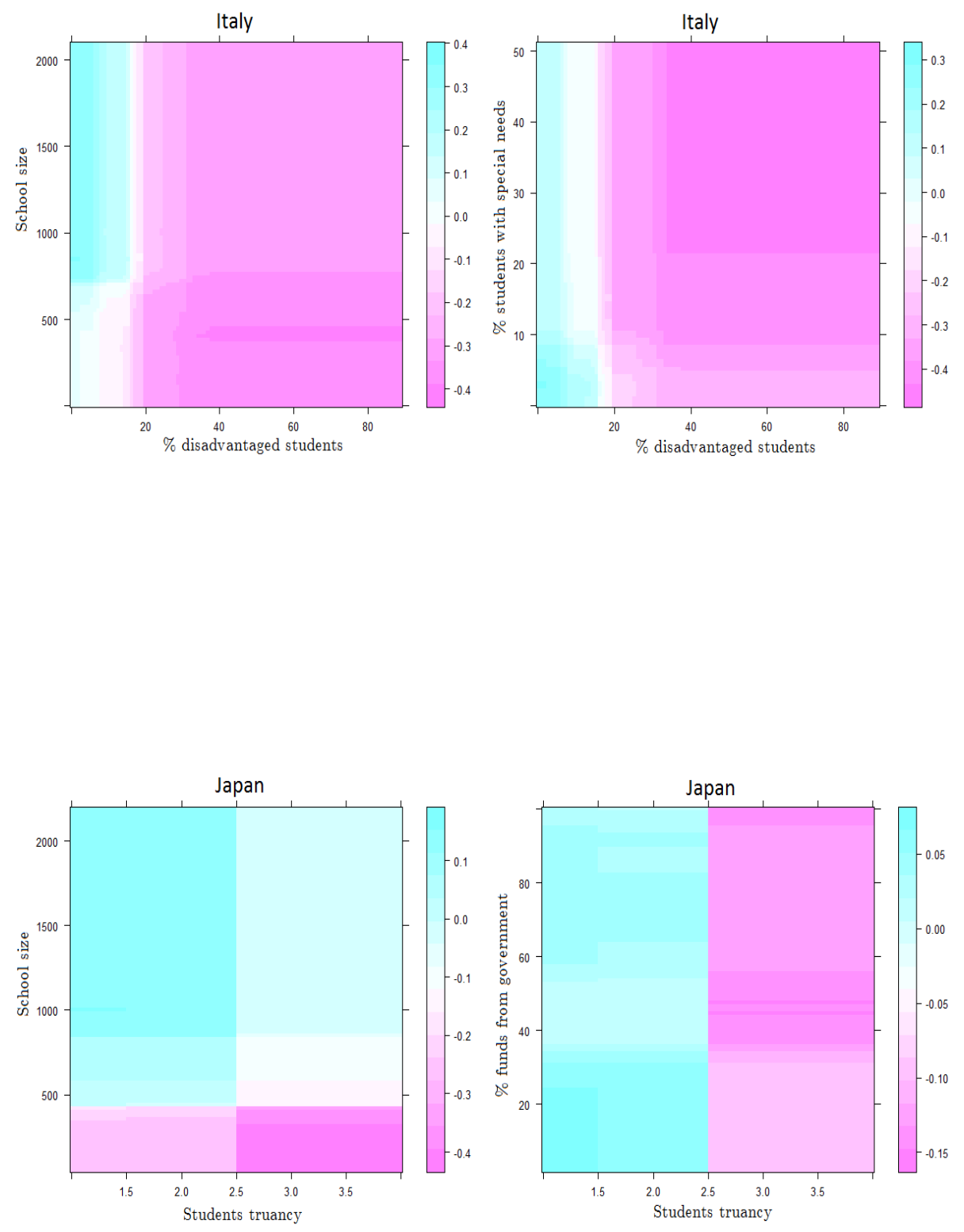

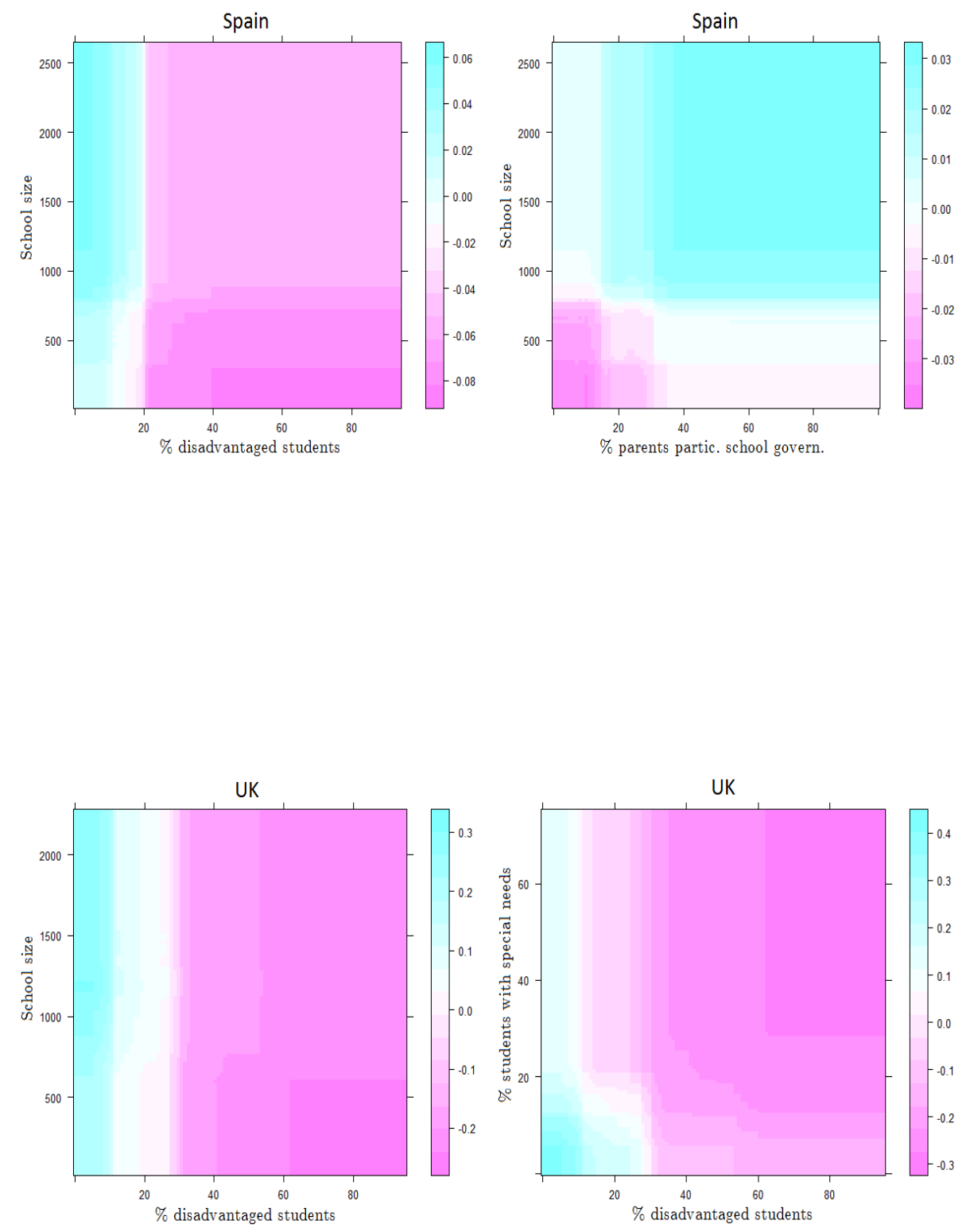

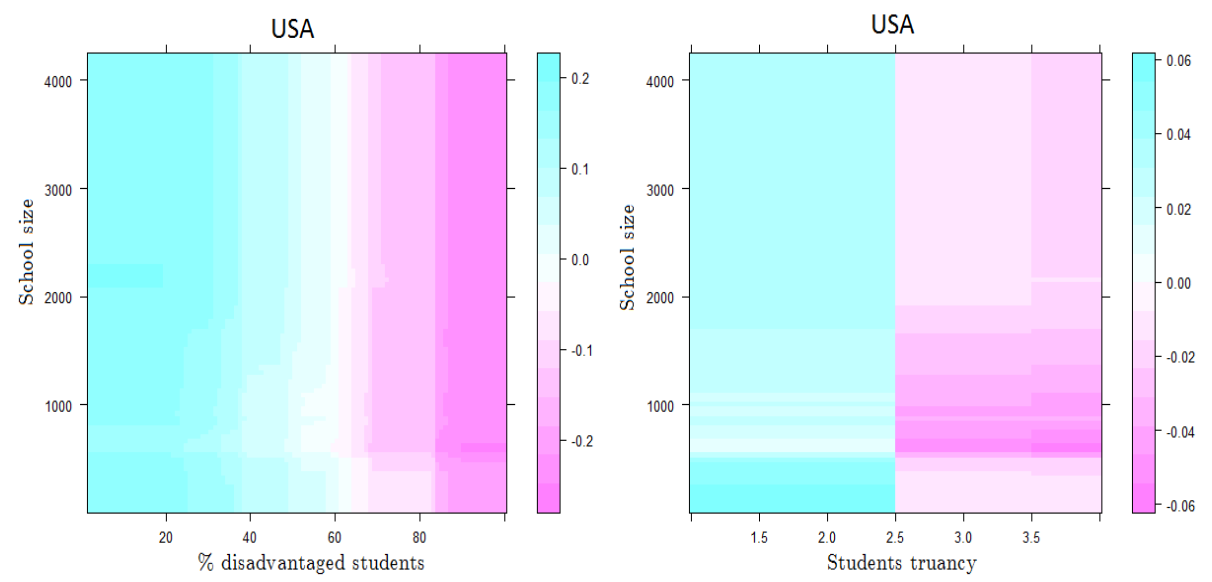

Figure 10: Joint partial plot of the most important school level variables in association with school value-added, in each country. Notes: 1 . Colors represent the scale of the values of the response (school value-added). 2. The selection of variables is based on the group of the variables that turn out to be significant in previous steps. 